\title{
əThe Dynamics of Observed Lee Waves over the Snæfellsnes Peninsula in Iceland
}

\author{
IoAna Colfescu, ${ }^{\text {a Joseph B. Klemp, }},{ }^{\mathrm{b}}$ Massimo A. Bollasina,,${ }^{\mathrm{c}}$ Stephen D. Mobbs, ${ }^{\mathrm{a}}$ And RAlPh R. Burton ${ }^{\mathrm{a}}$

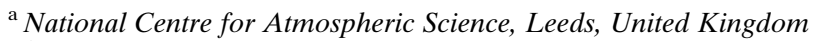 \\ ${ }^{\mathrm{b}}$ National Center for Atmospheric Research, Boulder, Colorado \\ ${ }^{\mathrm{c}}$ School of GeoSciences, University of Edinburgh, Edinburgh, United Kingdom
}

(Manuscript received 4 September 2020, in final form 29 January 2021)

\begin{abstract}
On 20 October 2016, aircraft observations documented a significant train of lee waves above and downstream of the Snæfellsnes Peninsula on the west coast of Iceland. Simulations of this event with the Weather Research and Forecasting (WRF) Model provide an excellent representation of the observed structure of these mountain waves. The orographic features producing these waves are characterized by the isolated Snæfellsjökull volcano near the tip of the peninsula and a fairly uniform ridge along its spine. Sensitivity simulations with the WRF Model document that the observed wave train consists of a superposition of the waves produced individually by these two dominant orographic features. This behavior is consistent with idealized simulations of a flow over an isolated 3D mountain and over a 2D ridge, which reproduce the essential behavior of the observed waves and those captured in the WRF simulations. Linear analytic analysis confirms the importance of a strong inversion at the top on the boundary layer in promoting significant wave activity extending far downstream of the terrain. However, analysis of the forced and resonant modes for a two-layer atmosphere with a capping inversion suggest that this wave train may not be produced by resonant modes whose energy is trapped beneath the inversion. Rather, these appear to be vertically propagating modes with very small vertical group velocity that can persist far downstream of the mountain. These vertically propagating waves potentially provide a mechanism for producing near-resonant waves farther aloft due to interactions with a stable layer in the midtroposphere.
\end{abstract}

KEYWORDS: Atmospheric circulation; Mesoscale processes; Mountain waves; Orographic effects; Waves, atmospheric; Regional models

\section{Introduction}

Internal gravity waves are frequently produced in the atmosphere when stably stratified air flows over mountainous terrain (Smith 1979). If these waves are sufficiently strong they can lead to hazardous weather conditions such as downslope windstorms (Lilly 1972; Klemp and Lilly 1975) that can produce widespread damage on the lee slope of major mountain ranges, and high-altitude clear-air turbulence that adversely affects aviation (Lilly 1978, Abernethy 2008). Previous studies have extensively documented such flows over major mountain ranges around the world such as the Rocky and Blue Ridge Mountains (Lilly 1978; Smith 1976), the Alps (Flamant et al. 2004), mountain ranges over Greenland (Petersen et al. 2009), the Falkland Islands (Mobbs et al. 2005), and ranges of mountains in South Georgia, Antarctica (Jackson et al. 2018). Such studies have based their analyses on observational evidence from research aircraft observations (Lilly 1978; Smith 1987; Wobrock et al. 1997; Jiang and Doyle 2005; Grubišić et al. 2008; Strauss et al. 2015; Fritts et al. 2016), together with analytical and numerical approaches, ranging from idealized analyses (Scorer 1949, Klemp and Lilly 1975) to complex numerical simulations (Doyle and Durran 2002). Numerical simulations

\footnotetext{
D Denotes content that is immediately available upon publication as open access.
}

Corresponding author: Ioana Colfescu, ioana.colfescu@ncas. ac.uk and linear theory studies (Vosper 2004; Schär and Durran 1997) have described various aspects of lee waves, such as their role in redistributing energy and momentum in the atmosphere and the influences of finescale atmospheric structures, such as temperature inversions, on the waves (e.g., Klemp and Lilly 1975; Durran 1986; Wang and Lin 2000; Vosper 2004). However, our understanding of the mechanisms of formation of gravity waves and their interaction with the environment are far from complete due to a number of compounding factors, including the limited observational evidence as well as difficulties in accurately representing the physical processes in numerical models (Vosper et al. 2018).

Significant lee-wave activity has also been documented and analyzed in lesser-known mountainous regions, one of interest here being Iceland where the occurrence of strong downslope winds and upper-level clear-air turbulence have been occasionally observed (Bramberger et al. 2020; Agústsson and Olafsson 2014). While rapid increases in wind speed linked to significant wave-induced hazards in the lee of the high terrain are particularly frequent in northern Iceland (Ruff and Olafsson 2019), strong wind gusts (commonly exceeding $20 \mathrm{~m} \mathrm{~s}^{-1}$ ) have also been observed and numerically simulated on the Snæfellsnes Peninsula in western Iceland (Agústsson and Olafsson 2009). The terrain that makes up the Snæfellsnes Peninsula has an interesting character, being comprised of a fairly uniform ridge along the spine of the peninsula, separated by a gap from the nearly kull volcano that forms the tip of the peninsula. While previous studies on orographic waves over the Snæfellsnes Peninsula focused primarily on surface wind characteristics, this work makes use of a unique set of aircraft measurements 
a)

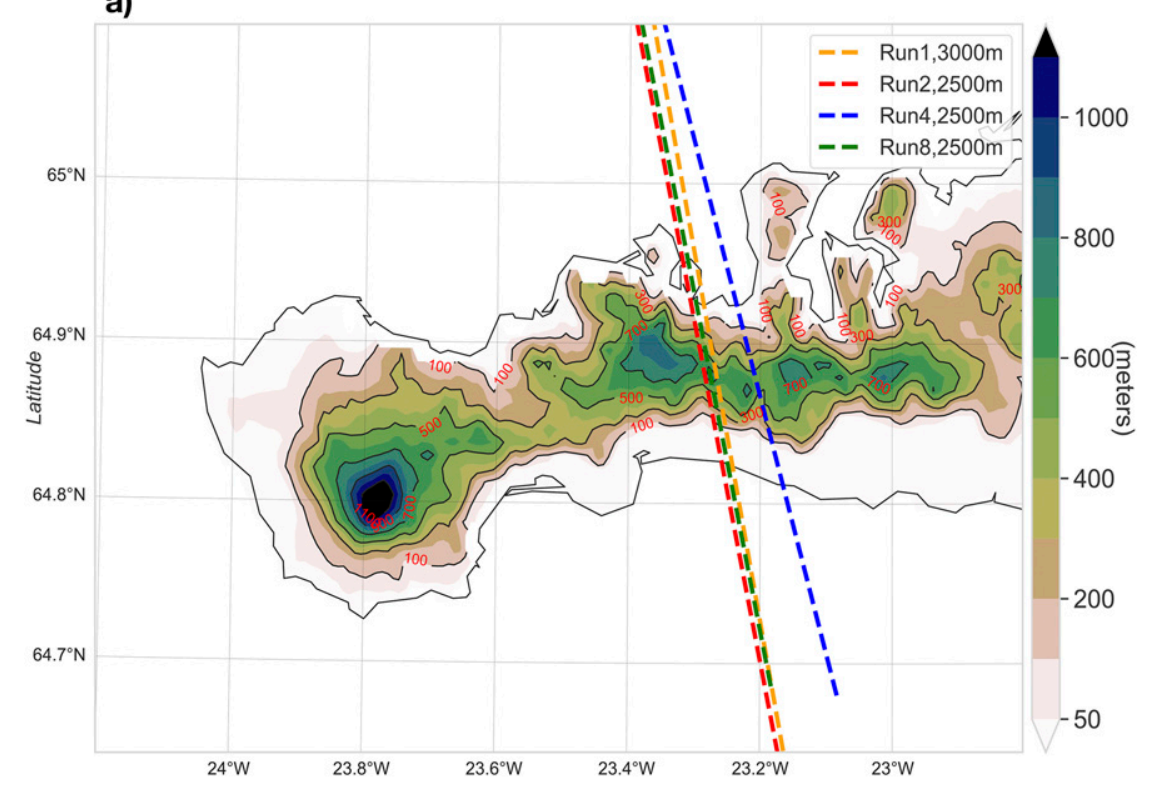

b)

Longitude

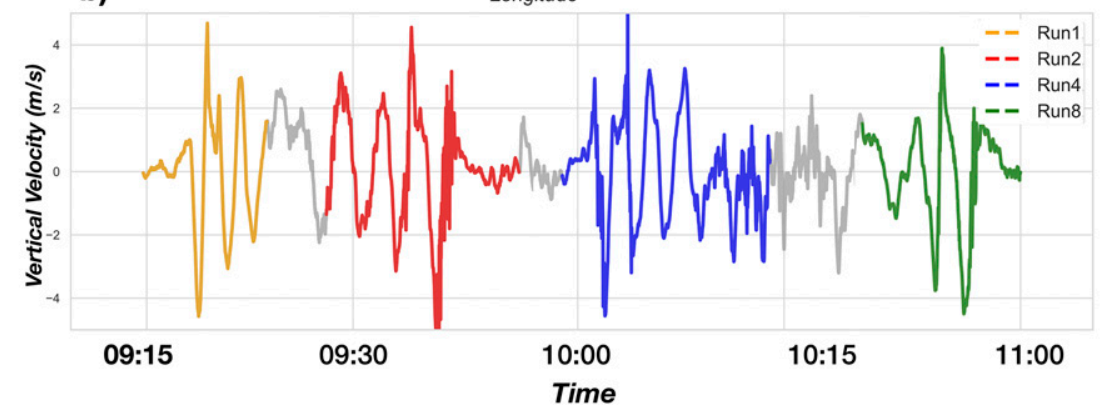

FIG. 1. (a) Topographic map of Snæfellsnes Peninsula in Iceland in meters [data from NOAA/NGDC GLOBE: Gridded $1 \mathrm{~km}$, quality-controlled global Digital Elevation Model (DEM) data from the Global Land One-km Base Elevation (GLOBE) Project] with overlapped flight tracks. (b) Vertical velocities along the flight tracks in (a).

obtained on 20 October 2016 to analyze the dynamics of these observed lee waves. The observations are complemented by a set of simulations with the regional Weather Research and Forecasting (WRF) Model as well as by idealized 2D and 3D simulations and linear analytic analyses to document the dynamics that govern the observed wave structure and its generation mechanisms by the complex regional topography.

The rest of the manuscript is organized as follows: section 2 describes the measurements taken and the key characteristics of the lee waves observed over the Snæfellsnes Peninsula on 20 October 2016. The configuration of the WRF Model used to simulate this case and the experiments conducted are provided in section 3 , followed by a comparison of the simulated results with observational data in section 4 . Section 5 presents the results of idealized simulations of $2 \mathrm{D}$ flow over a ridge and $3 \mathrm{D}$ flow past a circular mountain and their comparison with the more realistic WRF simulations. Section 6 derives the analytic solutions for a two-layer atmosphere in which a neutrally stable boundary layer is capped by a sharp inversion to demonstrate that the observed lee waves are consistent with vertically propagating modes rather than resonant modes trapped by the low-level inversion. In section 7 , we present the linear eigenvalue solution for the observed upwind atmospheric sounding and demonstrate that near-resonant waves are supported in the midtroposphere that may further amplify these vertically propagating modes. Finally, a summary of our results is provided in section 8 .

\section{Observed lee waves over the Snæellsnes Peninsula}

During the fall of 2016, a flight of the U.K. Facility for Airborne Atmospheric Measurements (FAAM) aircraft was conducted around the Snæfellsnes Peninsula in Iceland in order to observe a predicted (from operational forecasts) leewave event. The peninsula is bounded to the west by the $1446 \mathrm{~m}$ Snæfellsjökull volcano, with a ridge along the body of the peninsula that has an average height of about $500 \mathrm{~m}$ (Fig. 1). The overall length of the peninsula is about $80 \mathrm{~km}$ and the base of the volcano at the western tip is about $25 \mathrm{~km}$ 


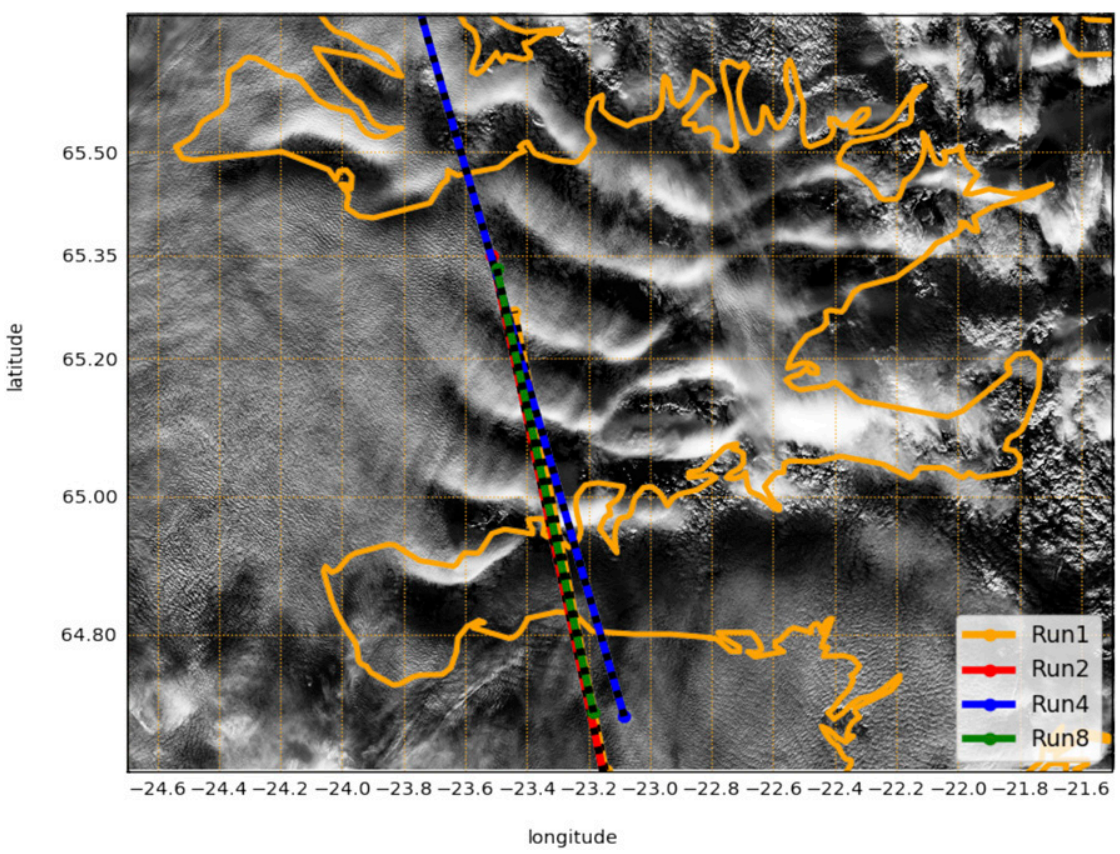

FIG. 2. Satellite image, Sentinel band 9, at 1352 UTC 20 Oct 2016 (https://sentinel.esa.int/) with flight tracks $\left(\mathrm{m} \mathrm{s}^{-1}\right)$ for flights $1,2,4$, and 8 , for 20 Oct 2016 FAAM flights.

(west-east) $\times 20 \mathrm{~km}$ wide (south-north). The average elevation along the ridge gradually increases from the east to west where the highest summits are found. In this study, we will consider the mountain waves observed both in the lee of the central part of the peninsula and in the lee of the more isolated Snæfellsjökull volcano.

On 20 October lee waves were observed and documented by the FAAM aircraft. The satellite image in Fig. 2 (Sentinel band 9 at 1352 UTC from ESA Sentinel Online) shows two lee-wave trains to the north of the peninsula, one that appears to be triggered by the peninsula itself and another triggered by the Snæfellsjökull mountain at the tip of the peninsula. As synoptic charts showed, the waves originated from strong southerly flow with a temperature inversion at $800-900 \mathrm{hPa}$ in the early morning of 19 October; $24 \mathrm{~h}$ later the wind direction changed to southwesterly and the wave pattern shifted accordingly. At 1200 UTC 20 October the upper-level sounding at Keflavík International Airport, about $100 \mathrm{~km}$ southeast of the peninsula (Fig. 3, solid lines), showed a strong temperature inversion at the top of the boundary layer at $850 \mathrm{hPa}(\sim 1300 \mathrm{~m} \mathrm{MSL})$. Although Keflavík is to the SSE of the peninsula and therefore not directly upwind in the presence of southwesterly winds, we expect that this sounding provides a reasonable representation of the flow impinging on the peninsula. The sounding also indicates that the air was nearly saturated under the inversion capping the boundary layer and within a midtropospheric stable layer at approximately 500-620 hPa.

The flight paths along which the observations were collected are plotted on the satellite image shown Fig. 2. The total flight consisted of 8 traverses (Table 1); waves were measured at two levels, 2.5 and $3 \mathrm{~km}$, over and to the lee of the peninsula. The winds were southwesterly (Fig. 3, wind barbs) and therefore the traverses crossed first through a wave created by the ridge along the peninsula and then into the wave train originating from the volcano at the western tip (the flight track was not aligned accurately along the mean wind direction). The individual flight tracks are displayed in Fig. 1 (top) along with the

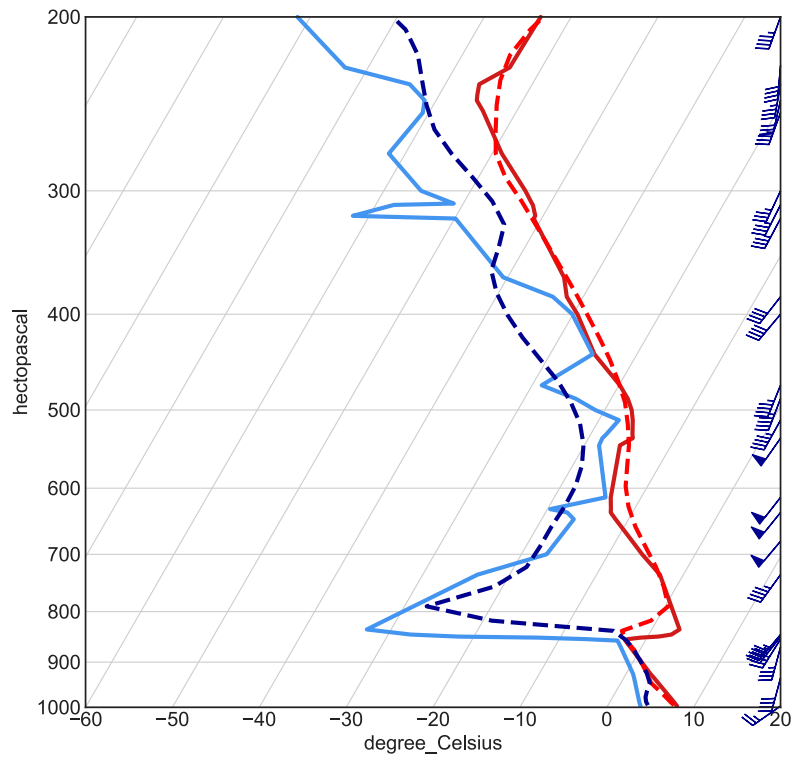

FIG. 3. Observed atmospheric vertical profile of temperature (red) and humidity (blue), obtained from radiosonde measurements (solid lines) and the $400 \mathrm{~m}$ E1 WRF simulation (dashed lines) at 1200 UTC 20 Oct 2016 in Keflavík, Iceland. The wind barbs are in knots. 
TABLE 1. FAAM flights for 20 Oct 2016. Times are in UTC and $1 \mathrm{kft} \approx 305 \mathrm{~m}$.

\begin{tabular}{cccccc}
\hline \hline Run & Start & End & $\begin{array}{c}\text { Duration } \\
(\mathrm{min})\end{array}$ & $\begin{array}{c}\text { Altitude } \\
(\mathrm{kft})\end{array}$ & $\begin{array}{c}\text { Heading } \\
(\mathrm{N} \text { or S })\end{array}$ \\
\hline 1 & 0914 & 0923 & 9 & 10 & $\mathrm{~N}$ \\
2 & 0928 & 0942 & 14 & 8 & $\mathrm{~S}$ \\
3 & 0950 & 0952 & 2 & 2.5 & $\mathrm{~N}$ \\
4 & 0958 & 1013 & 15 & 8 & $\mathrm{~N}$ \\
5 & 1017 & 1024 & 6 & 8 & $\mathrm{~S}$ \\
6 & 1033 & 1039 & 5 & 2 & $\mathrm{~S}$ \\
7 & 1041 & 1043 & 2 & 2 & $\mathrm{~N}$ \\
8 & 1048 & 1100 & 12 & 8 & $\mathrm{~S}$ \\
\hline
\end{tabular}

vertical velocity profiles along the tracks (bottom). In this study, we will focus on the flight legs labeled Run1, Run2, Run4, and Run8 (Table 1 and Fig. 1). The first traverse (Run1) was recorded around 0930 UTC and the last one (Run8) was at about 1100 UTC; the observed vertical velocities over the Runs $1,2,4$, and 8 document a consistent wave pattern that is reasonably stationary in time and space during the observation period. The flight levels were restricted by the meteorological conditions. In particular, a cloud layer between 3000 and $6500 \mathrm{ft}$ prevented any data from being collected within this height range.

\section{WRF Model configuration}

Simulations of these observed mountain waves are conducted with the WRF Model, version 3.8.1 (Skamarock et al. 2019). WRF is a fully compressible nonhydrostatic model, with a terrain-following hybrid vertical coordinate and with horizontal and vertical Arakawa $\mathrm{C}$ grid staggering. Each experiment is configured with four one-way nested domains at horizontal grid resolutions of $50 \mathrm{~km}, 10 \mathrm{~km}, 2 \mathrm{~km}$, and $400 \mathrm{~m}$ (Fig. 4) centered at $64.3^{\circ} \mathrm{N}, 18.3^{\circ} \mathrm{W}$. In addition to the simulations presented in this study, additional sensitivity simulations were performed to ensure that no artificial effects arose due to the proximity of the lateral boundary. Each simulation uses 60 vertical sigma-pressure levels from the surface up to $100 \mathrm{hPa}$ with the first level at approximately $25 \mathrm{~m}$. The variables from the highest-resolution simulation ( $400 \mathrm{~m}$ horizontal resolution, with output every $3 \mathrm{~min}$ ) are used for the wave analysis presented below.

A damping layer is included in the upper boundary, with a 5-km-deep implicit gravity wave damping layer beneath the model top. The WRF simulations are run from 0000 to 1200 UTC 20 October 2016. Initial and 6-hourly lateral boundary conditions for the coarser domain simulation are taken from the National Centers for Environmental Prediction (NCEP) operational Global Forecast System (GFS) forecast data on a $0.5^{\circ} \times 0.5^{\circ}$ global latitude-longitude grid. All of the simulations use the Morrison microphysics scheme (Morrison et al. 2005), the MYJ PBL scheme, (Janjić 1994), the KainFritsch cumulus parameterization (Kain 2004), the Dudhia shortwave radiation (Dudhia 1989), the rapid radiative transfer model longwave radiation (Mlawer et al. 1997), and the Noah land surface model (Tewari et al. 2004). More information

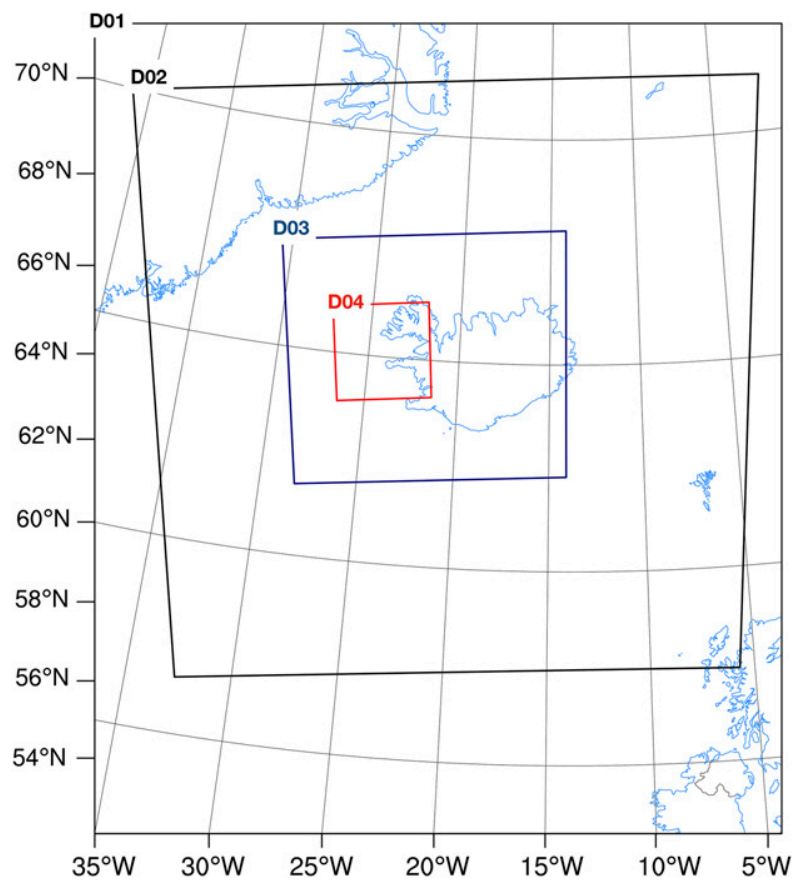

FIG. 4. WRF simulation domains. The corresponding horizontal resolutions are $50 \mathrm{~km}$ (D01), $10 \mathrm{~km}$ (D02), $2 \mathrm{~km}$ (D03), and $400 \mathrm{~m}$ (D04).

about these physics options can be found in Skamarock et al. (2019). These choices correspond to the default namelist options in WRF, and are used because simulation of the dynamics of the observed gravity waves should not be particularly sensitive to the particular choice of physics.

We present here a total of three experiments, a control case with the full orography, and two sensitivity experiments (Table 2). The control simulation, called E1 or "Full Orography," uses the actual orography of the Snæfellsnes Peninsula. The sensitivity experiments are similar to E1 except that either the Snæfellsjökull volcano is removed (called E2, or "No Mountain") or the ridge along Peninsula is removed (called E3, or "No Ridge"). Here, the orography is altered by multiplying the affected terrain by 0.1 , leaving the rest of the simulation unchanged. Figure 5 displays the orography in the three experiments at $400 \mathrm{~m}$ resolution, along with the corresponding flight tracks interpolated to the model grid. We did not run an ensemble of simulations since the wave features reproduced by the initial single WRF run agree well with the observations and the purpose of the study was not to quantify the uncertainty in the representation of the wave in WRF.

\section{Analysis of the WRF simulations}

\section{a. Full orography simulation}

We begin by comparing the "full orography" WRF simulation E1 to aircraft observations to demonstrate that the model provides a credible depiction of the background environmental conditions as well as of wavelength, phase, and amplitude of the observed waves. Here, we focus mainly on the 
TABLE 2. Description of the WRF experiments.

\begin{tabular}{|c|c|c|c|}
\hline Name/expt details & Resolution, PBL, microphysics & Orography & Boundary conditions \\
\hline Control (E1) & $400 \mathrm{~m}, \mathrm{MYJ}$, Morrison & Realistic orography & GFS, $0.5^{\circ}$ \\
\hline No mountain (E2) & As in $\mathrm{E} 1$ & $\begin{array}{l}\text { Orography over Snæfellsjökull volcano multiplied } \\
\text { by } 0.1\end{array}$ & As in $\mathrm{E} 1$ \\
\hline No ridge (E3) & As in E1 & Orography over the ridge multiplied by 0.1 & As in E1 \\
\hline
\end{tabular}

vertical velocity field, which provides an informative representation of the fundamental wave structure.

Figure 3 shows the comparison between the observed and simulated (E1) vertical sounding at Keflavík at 1200 UTC and indicates an overall good agreement between the two throughout the troposphere. WRF (dashed line) reproduces the strong temperature inversion at $850 \mathrm{hPa}$ and also the midtropospheric one (albeit somewhat weaker than observed). The simulated wind profile is also close to observations (not shown). The main discrepancy between WRF and observations is that WRF tends to be wetter than observations in the lower troposphere, and underestimates the humidity at midlevels.

The horizontal plan view of the vertical velocity in the E1 simulation is displayed in Fig. 6 for the $700 \mathrm{hPa}$ level and shows extensive wave trains forming in the lee of both the volcano and the ridge portion of the peninsula, consistent with the wave pattern visible in the satellite image (Fig. 2). In the E1 simulation the mountain waves have horizontal wavelengths of about $12.5 \mathrm{~km}$ and remain quasi-stationary for several hours, with the maximum intensity occurring between 0900 and 1130 UTC. The aircraft flight tracks, also depicted in Fig. 6, traverse the wave trains in the lee of the peninsula at an oblique angle, such that moving from south to north along the flight paths, the track first crosses what appears to be the "ridge generated" waves (up to $64.95^{\circ} \mathrm{N}$ ) and then enters into the wake of the "mountain generated" waves. A separation in the phase of the two wave trains is clearly evident in the $\mathrm{E} 1 \mathrm{nu}-$ merical simulation (Fig. 6).

The vertical cross section of vertical wind speed, $w\left(\mathrm{~m} \mathrm{~s}^{-1}\right)$ for the Run1 flight path (depicted by the yellow dotted line in Fig. 6) is shown in Fig. 7. Significant wave activity is confined to the troposphere with maximum vertical velocity in the midtroposphere, well above the height of the low-level inversion. Above the tropopause $(\sim 10 \mathrm{~km})$, the wave amplitude is much weaker and does not extend very far downstream. In the stratosphere, the lines of constant phase tilt upstream with increasing height, which is consistent with upward-propagating wave energy with no apparent artificial reflection from the upper boundary. There is no sign of overturning of the waves in the horizontal velocity fields (not shown).

The lower-tropospheric $w$ contours for the E1 simulation along with the observed and simulated profiles for the vertical velocities along each of the four flight tracks are depicted in Fig. 8. Good similarity can be seen in the amplitude, phase, and wavelengths between the observed and simulated waves for Run1, Run2, and Run8. For Run4, while the simulated wave amplitude agrees well with the observed profile, the difference in phase increases with increasing distance from the lee of the peninsula. The double peak structure present in the first wave along the track in Run1 (Fig. 8a) is reproduced by the model simulation. The double maximum in the first wave crest can be attributed to the flight track passing first through the wave crest caused by the ridge and then passing immediately into the one caused by the isolated mountain, and will be discussed further below. The flight track data also suggest that the lee-wave response is beginning to weaken by the time of the last traverse (track 8 ). Although the altitude and direction of the track are virtually the same as for track 2 , the downstream amplitude of the waves is noticeable lower.

\section{b. Sensitivity experiments}

We analyze here the two sensitivity experiments E2 and E3 that have the altered orographic features as described in section 3 , designed to gain further insights into the wave formation forced by the individual orographic features.

The $700 \mathrm{hPa}$ vertical velocities in the E2 and E3 simulations are shown in Fig. 9. The "No Mountain" experiment E2 (Fig. 9a) features an extensive wave train extending downwind (northeast) of the ridge with nearly linear crest and trough lines aligned parallel to the ridge. Similarly, in the "No Ridge" experiment E3 (Fig. 9b), a train of lee waves extends downstream of the isolated Snæfellsjökull volcano. As in the case of the full orography experiment E1, the vertical velocity exhibits maximum values of about $4-4.5 \mathrm{~m} \mathrm{~s}^{-1}$ and the mountain waves remain nearly stationary for the hours between 0900 and 1130 UTC (not shown). Interestingly, the combination of the waves generated separately by E2 and E3 (i.e., E2 + E3) is in close agreement with that produced with the full orography (E1) as indicated by the difference plot in Fig. 9c, suggesting that the wave responses to the individual terrain features (mountain and ridge) are additive, with little indication of wave-wave (nonlinear) interactions.

This additive behavior is further supported by the vertical velocity profiles along the flight paths in Runs 1, 2, 4, and 8 for the E1, E2, and E3 simulations and observations shown in Fig. 10. Along each of these tracks, the sum of the vertical velocities in the E2 and E3 simulations agrees well with the vertical velocity profile in the full orography (E1) simulation. These profiles also confirm that the flight tracks moving from south to north pass first through the wave generated by the ridge and then transition abruptly into the wave train behind the volcano. For each of these runs, the E2 $w$ profile (yellow) follows the E1 (green) and observed (purple) profiles closely through the first wave trough and into the first major wave crest. On the back side of this crest (around $65^{\circ} \mathrm{N}$ ), the E2 $w$ decreases rapidly while the $\mathrm{E} 3 w$ (red) increases in response to the wave crest in the lee of the volcano. Moving farther downstream (north), the amplitude of the E3 $w$ profile is very 


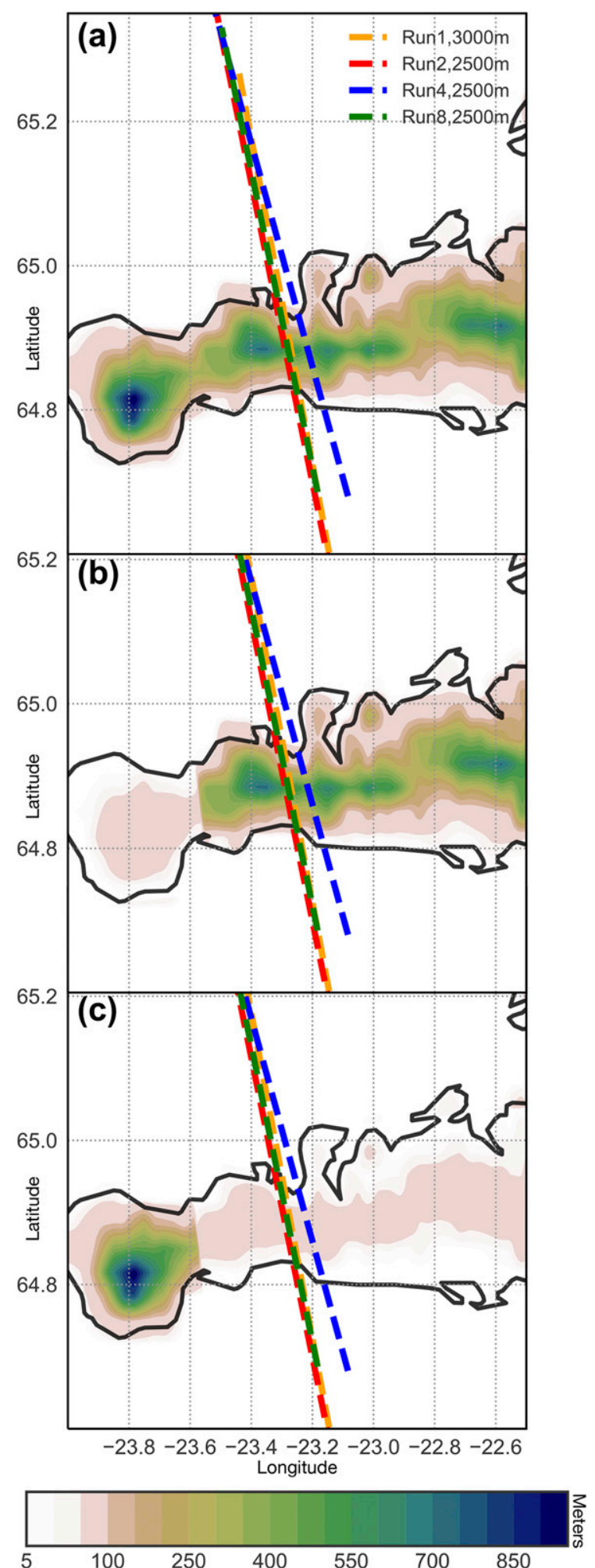

FIG. 5. Orography of the Snæfellsnes Peninsula used for the (a) E1 (full orography), (b) E2 (no mountain), and (c) E3 (no ridge) WRF simulations, with the aircraft flight tracks superimposed.

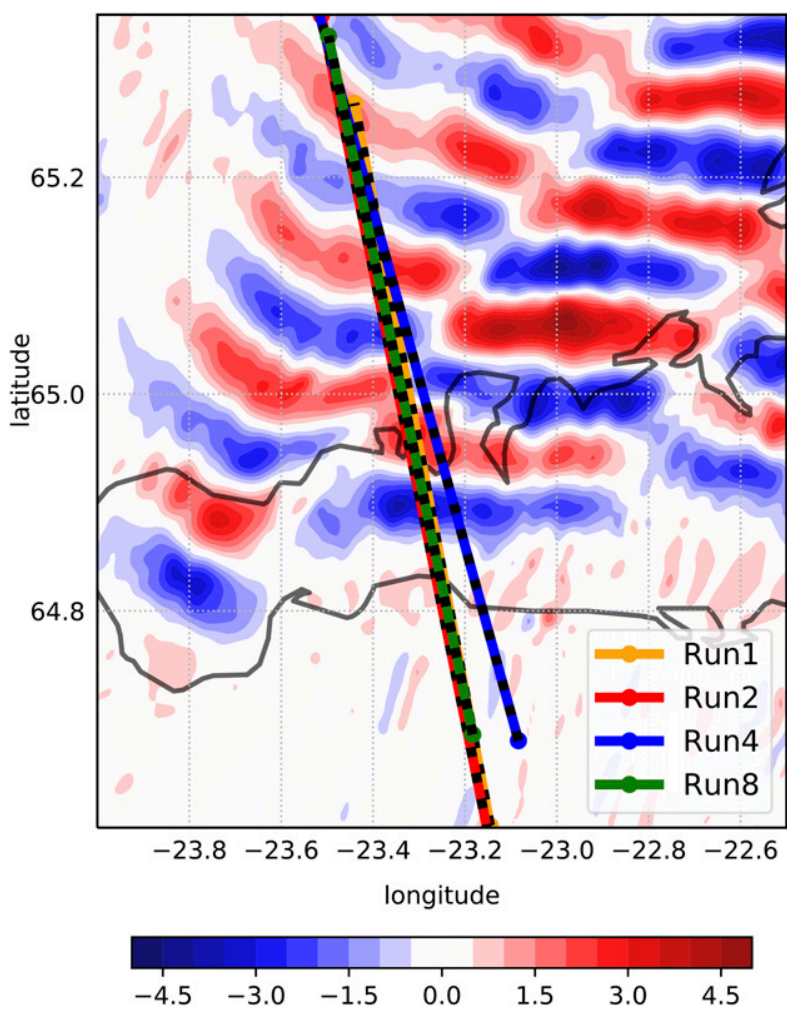

FIG. 6. Vertical velocity $w\left(\mathrm{~m} \mathrm{~s}^{-1}\right)$ at $700 \mathrm{hPa}$ in the WRF simulation E1 at the time of Run1 together with the flight tracks of Run1, Run2, Run4, and Run8.

close to the E1 $w$ amplitude while the $\mathrm{E} 2 w$ amplitude becomes small. Thus, the observed double peak in the first major wave crest along the flight tracks in Run1, Run2, and Run4 appears because the aircraft passed from the crest of the wave produced by the ridge directly into the crest of the wave generated by the volcano. This behavior will be discussed further in conjunction with the idealized simulations in the next section.

\section{2D and 3D simulations of idealized lee waves}

The WRF simulations discussed above suggest that the lee waves observed on 20 October 2016 downstream of the Snæfellsnes Peninsula are well represented by the superposition of the waves produced by the ridge along the spine of the peninsula and those generated by the more isolated Snæfellsjökull volcanic cone near the tip of the peninsula. With this in mind, it should be possible to reproduce the basic characteristics of the waves in the lee of the ridge and the mountain through idealized simulations for 2D flow over a ridge and for 3D flow over an isolated 3D mountain, respectively.

To demonstrate the relevance of idealized wave structures to the observed lee waves, we have conducted 2D and 3D mountain wave simulations using an idealized prototype of the WRF Model numerics (Klemp et al. 2007). Here, we consider flow of a horizontally homogeneous atmosphere having temperature and wind profiles as depicted in the 1200 UTC 20 October 2016 Keflavik sounding in Fig. 3. For the simulation 


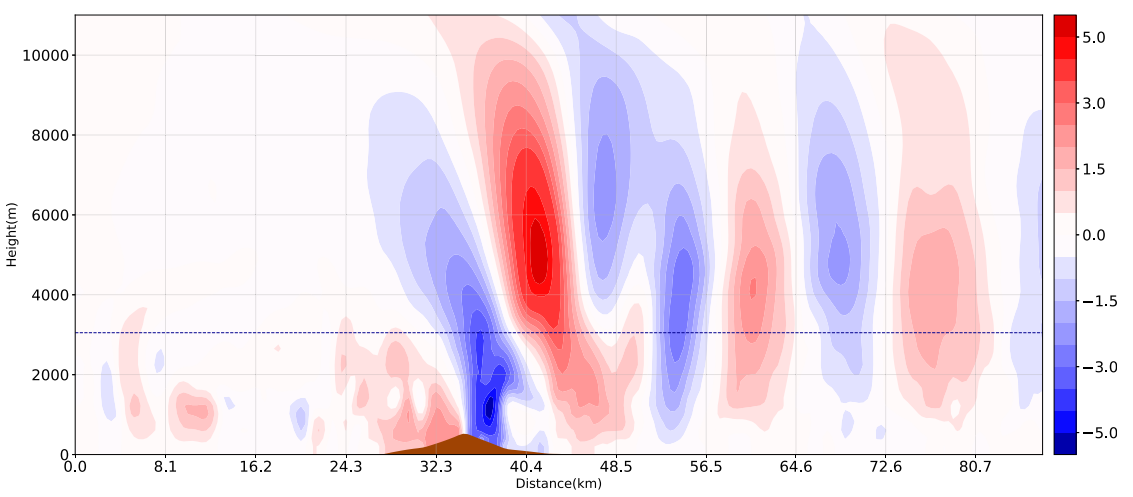

FIG. 7. Full-domain vertical cross section of cross-ridge vertical velocity $w\left(\mathrm{~m} \mathrm{~s}^{-1}\right)$ in the WRF simulation E1 along a flight track corresponding to Run1 at the time of this flight track. The underlying orography is plotted in brown.

of flow over a 2D ridge, the terrain corresponds to a bellshaped profile:

$$
h(x)=\frac{a^{2} H}{x^{2}+a^{2}},
$$

which is a reasonable approximation to the average cross section of the Snæfellsnes Peninsula with a maximum terrain height $H=500 \mathrm{~m}$ and a mountain half-width $a=2.5 \mathrm{~km}$. Simulations were conducted with a horizontal grid size $\Delta x=500 \mathrm{~m}$, and a stretched vertical mesh increasing from $\Delta z=100 \mathrm{~m}$ near the surface to $\Delta z \simeq 300 \mathrm{~m}$ near the model top at $z_{t}=25 \mathrm{~km}$. A gravity wave-absorbing layer as described by Klemp et al. (2008) is applied above $z_{t}=15 \mathrm{~km}$ to prevent artificial reflection of wave energy from the upper boundary. The nonhydrostatic equations are numerically integrated using the time-split numerics described in Klemp et al. (2007) with an overall time step of $3 \mathrm{~s}$ and an acoustic time step of $0.5 \mathrm{~s}$ out to $2 \mathrm{~h}$, at which time the flow fields were essentially at steady state $(U t / a \simeq 60)$.

The steady 2D vertical velocity field from this simulation at $2 \mathrm{~h}$ is displayed in Fig. 11, and reveals a wave train of horizontal wavelength approximately $12.8 \mathrm{~km}$ extending far downstream of the ridge. This corresponds well with the WRF simulation, in which the waves in the lee of the ridge have wavelength of about $12.5 \mathrm{~km}$ (Figs. 6 and 9). In both the full WRF simulation (Fig. 7) and the 2D idealized simulations (Fig. 11), the maximum wave amplitudes occur in the midtroposphere. As addressed further in the next section, this structure suggests that these waves are not trapped resonant waves, but rather are vertically propagating modes having a very small vertical group velocity, such that the wave energy propagates far downstream in the troposphere. Although the simulation depicted in Fig. 11 is fully nonlinear, it differs only slightly from a comparable linearized simulation (not shown), in which the wave amplitudes are just slightly weaker. This behavior justifies the further analysis of the resonant lee waves based on linear theory, presented in the next section.

For the idealized 3D simulation of flow over an isolated mountain, we specify the same environmental flow as in the 2D simulation, and the same model configuration, except that the domain now also extends in the cross-stream direction with $\Delta y=500 \mathrm{~m}$, and the mountain shape is defined as a circular bell [replacing the $x$ in (1) with the radial distance from the mountain peak, $r=\sqrt{x^{2}+y^{2}}$ ] having maximum height $H=$ $1300 \mathrm{~m}$. Figure 12a displays a vertical cross section of the vertical velocity field at $2 \mathrm{~h}$, taken along the centerline of the wave train downstream of the mountain. As in the 2D simulation for the ridge, the waves extend far downstream of the mountain with a similar $\sim 12.5 \mathrm{~km}$ horizontal wavelength and maximum amplitudes in the midtroposphere. However, in this $3 \mathrm{D}$ configuration, the maximum amplitudes of the waves decrease more noticeably with downstream distance as the wave energy in the $3 \mathrm{D}$ waves is also dispersing laterally. This lateral expansion is evident in the horizontal $w$ cross section at $3 \mathrm{~km}$ in Fig. 12b, corresponding to the level displayed for the WRF simulations in Fig. 6. This panel also displays an estimate of the approximate flight track relative to the wave train. Here the track is oriented such that it intersects the second, third, and fourth wave crests downstream of the mountain as it traverses the lee waves in a manner similar to that shown in Fig. 2 and the WRF cross section in Fig. 6. The vertical velocity profile interpolated to this hypothetical flight track is shown in Fig. 12c. This profile is semiquantitatively similar to the $w$ profile obtained in the "no ridge" WRF simulation depicted in Fig. 10. The horizontal wavelength along this path appears to increase with increasing distance downstream; this is to be expected since the profile cuts through the wave train at an oblique angle, and is consistent with the wavelengths observed along the actual flight path (see e.g., the observed $w$ profiles in Fig. 8).

As discussed above, the vertical velocity profiles observed along the flight track appear to be consistent with a combination of the wave trains in the lee of the ridge and in the lee of the isolated mountain, transitioning from the ridge-produced waves immediately downstream of the peninsula to those generated behind the mountain farther to the lee. We can speculate how this might be represented in our idealized 2D and 3D simulations by super imposing the two $w$ profiles in Figs. $11 \mathrm{~b}$ and $12 \mathrm{c}$ and horizontally positioning the $3 \mathrm{D}$ profile such that its first peak in $w$ is just downstream of the first significant peak in the 2D profile, as shown in Fig. 13. 

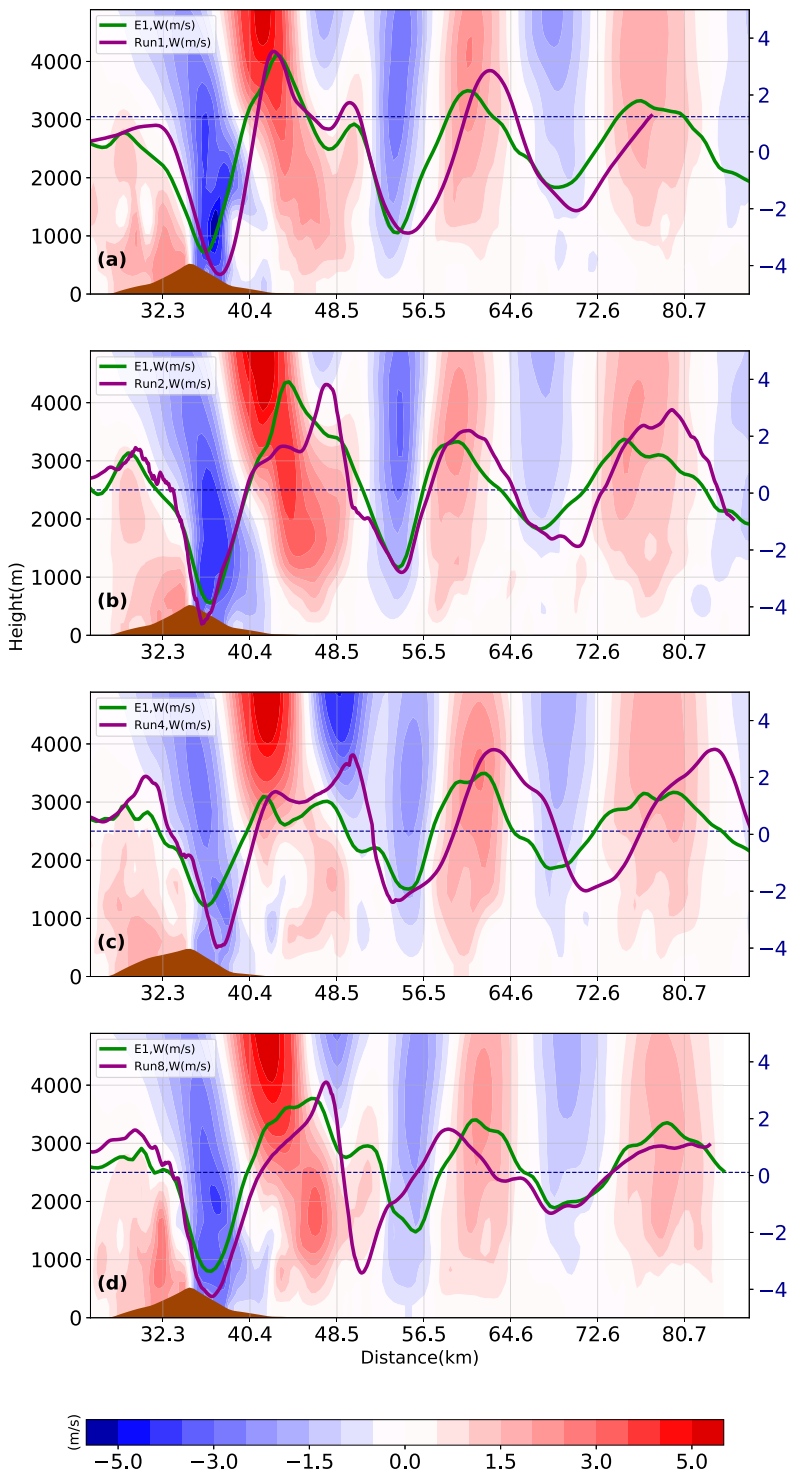

FIG. 8. Vertical cross section of cross-ridge vertical velocity $w\left(\mathrm{~m} \mathrm{~s}^{-1}\right)$ in E1 along flight tracks corresponding to (a) Run1, (b) Run2, (c) Run4, and (d) Run8. For each flight track, the corresponding observed $w$ is plotted in solid purple and its modeled counterpart (interpolated $w$ to the location along the flight track) is plotted in solid green. The right $y$ axis denotes the amplitude $\left(\mathrm{m} \mathrm{s}^{-1}\right)$ of the $w$ profiles (purple and green), while the left $y$ axis represents height $(\mathrm{m})$ of the shaded $w$ contours. The underlying orography is plotted in brown and the blue dotted line represents the height of each of the observed flights.

This behavior is consistent with the profiles displayed in the "no mountain" and "no ridge" WRF simulations shown in Fig. 10. Since these idealized simulations provide no information how the wave transitions from those produced by the ridge to those reduced by the mountain, we have arbitrarily terminated the ridge profile just downstream of the supposed crossover point and likewise terminated the mountain profile just upstream of this point. Nevertheless, this combined idealized $w$ profile has
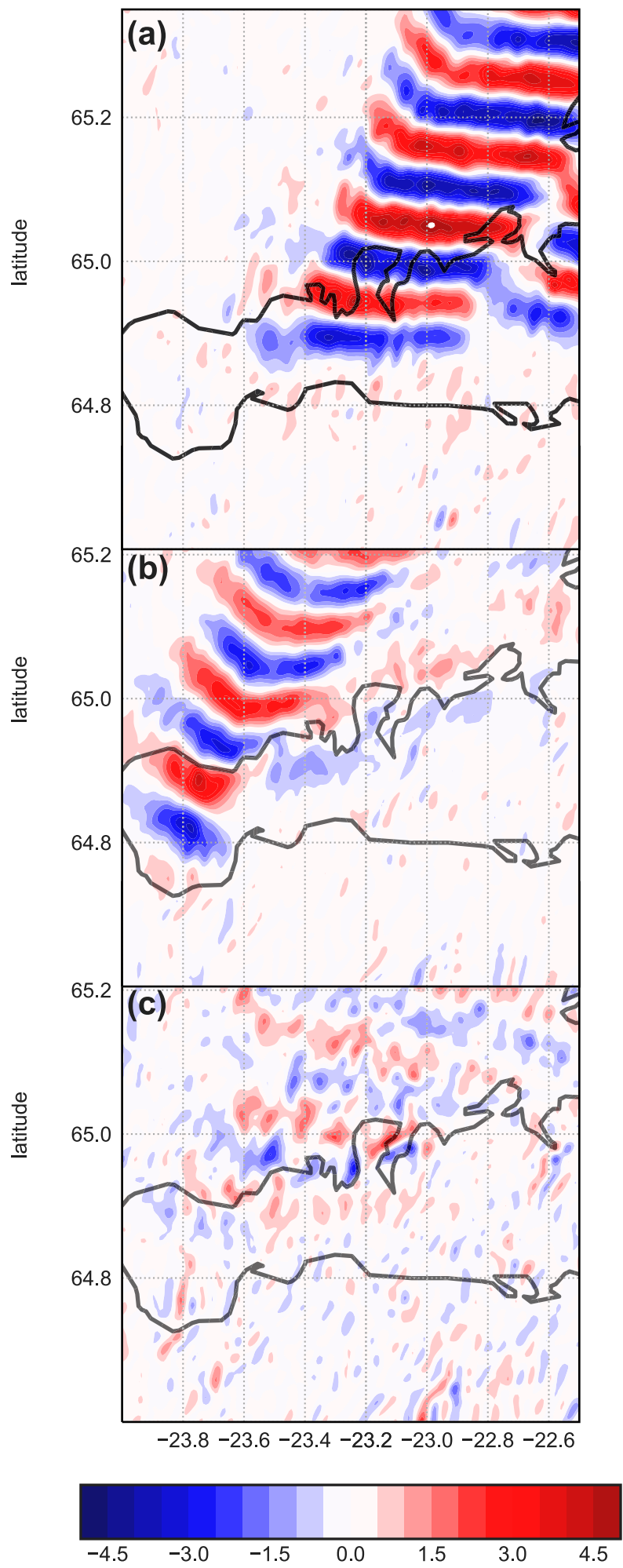

FIG. 9. Vertical velocity $w\left(\mathrm{~m} \mathrm{~s}^{-1}\right)$ at $700 \mathrm{hPa}$ for domain 4 (400 m) in the WRF simulations at the time of Run1: (a) E2, (b) E3, and (c) $\mathrm{E} 1-(\mathrm{E} 2+\mathrm{E} 3)$. 

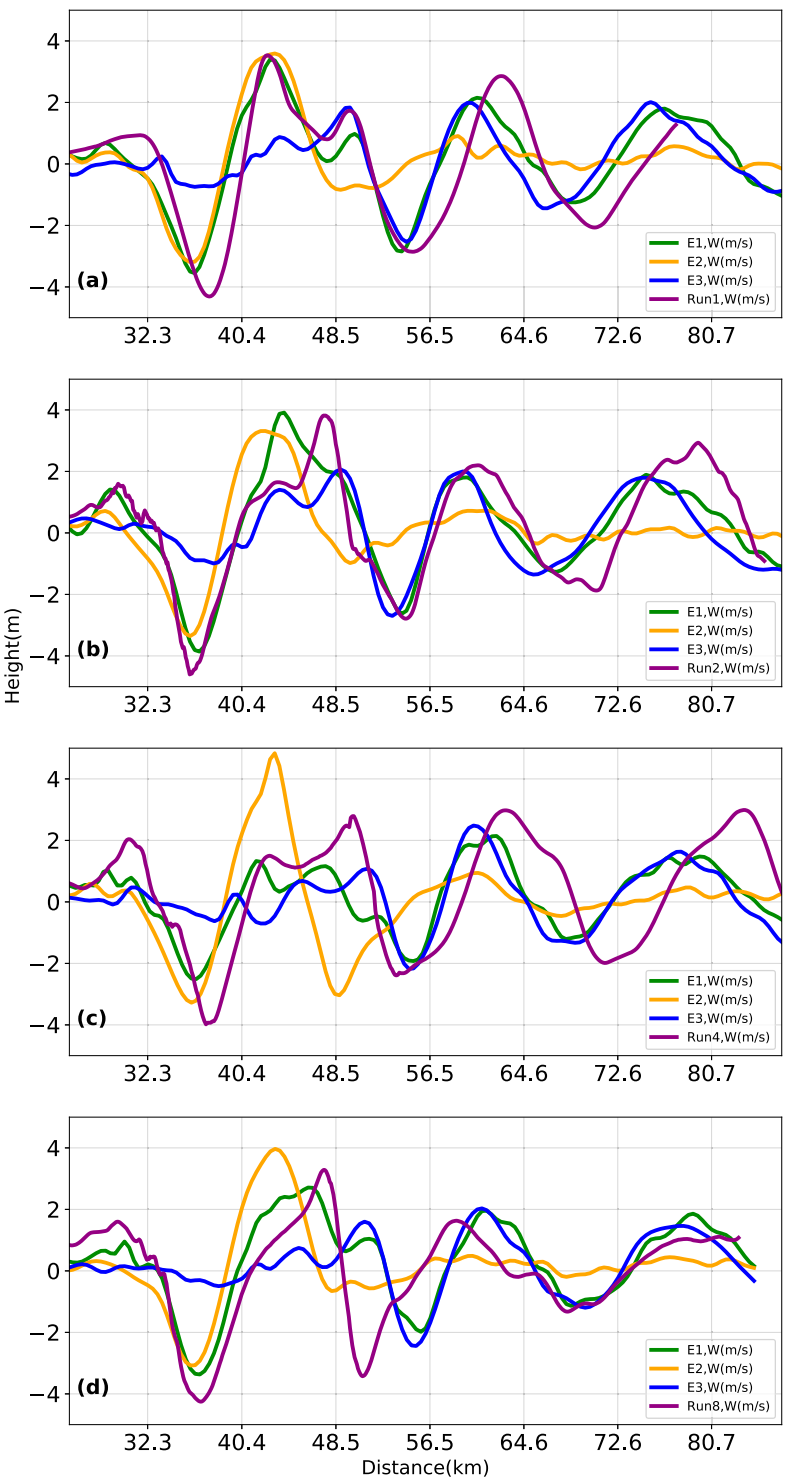

FIG. 10. Vertical velocity profiles $w\left(\mathrm{~m} \mathrm{~s}^{-1}\right)$ in simulations E1, $\mathrm{E} 2$, and E3, together with the observed $w$ along the flight tracks for (a) Run1, (b) Run2, (c) Run4, and (d) Run8.

many similarities to the observed and WRF-simulated profiles in Fig. 8, and provide further support for the interpretation that the observed double peak in first wave along the flight track is produced by the slightly offset superposition of wave crests produced by the ridge and by the isolated mountain.

\section{Linear analysis of lee waves produced by the low-level inversion}

Since a portion of the terrain of the Snæfellsnes Peninsula forms a long narrow ridge, mountain waves arising from flow normal to that portion of the peninsula may be reasonably represented in a two-dimensional framework. The wave train extending far downstream of the peninsula suggests that these
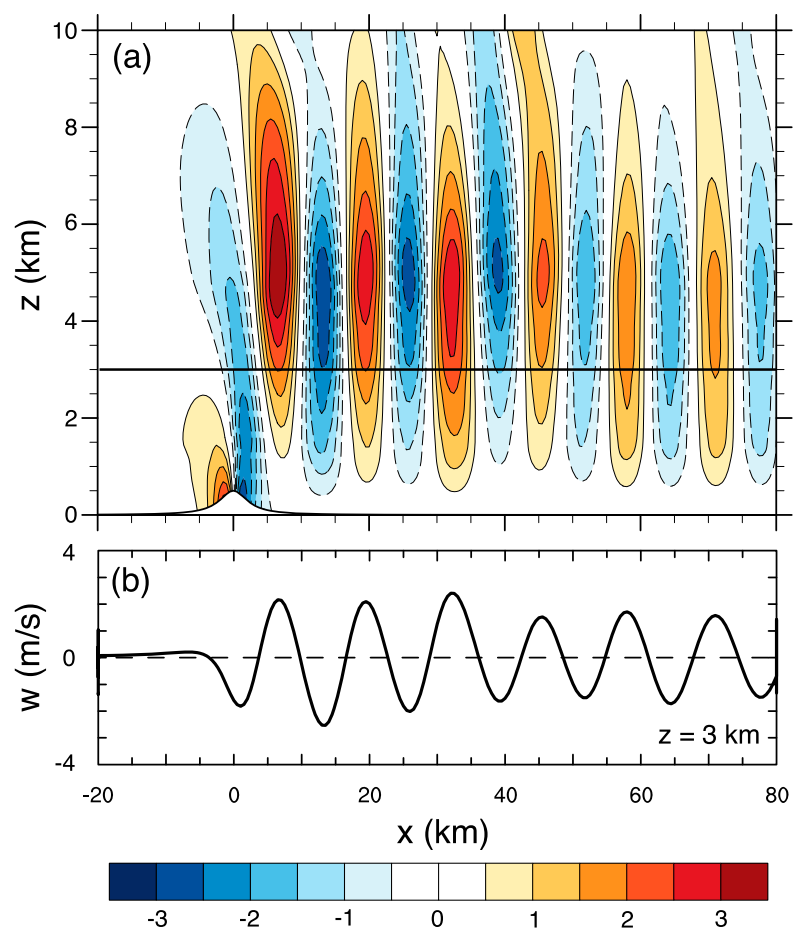

FIG. 11. Steady nonlinear vertical velocity for idealized lee-wave simulation for flow over a 2D $500 \mathrm{~m}$ bell-shaped ridge, with temperature and wind profiles corresponding to the 1200 UTC sounding from Keflavik (Fig. 3). (a) Vertical velocity cross section and (b) vertical velocity profile at $z=3 \mathrm{~km}$ taken perpendicular to the ridge.

may be trapped resonant lee waves. We further investigate the nature of these waves by analyzing solutions of the 2D linear steady-state wave equations. To maintain reasonable similarity with the observed upwind sounding displayed in Fig. 3, we analyze here linear solutions for an atmosphere with uniform mean wind $U$ and a two-layer thermodynamic profile characterized by a neutrally stable boundary layer of depth $z_{i}$ capped by a sharp inversion of strength $\Delta \theta$, with a semi-infinite layer of constant stability $N$ aloft. This atmospheric structure is the same as that analyzed by Vosper (2004), who evaluated the characteristics of the trapped resonant lee waves that may arise in the steady linear solutions for this two-layer mean flow. However, the characteristics of the mountain lees may depend strongly on features of both the vertically propagating waves and the resonant lee waves (Nappo 2012). Therefore, we extend the linear analysis of Vosper (2004) to derive full linear solutions that can clarify the behavior of the linear theory for this idealized environment and demonstrate its relevance to the observed lee waves over the Snæfellsnes Peninsula.

\section{a. Linear wave equation}

Solutions to the linear nonhydrostatic equations require analysis of the individual Fourier wave modes followed by the reconstruction of the full flow field for a particular mountain profile. For this purpose we consider flow over a 2D ridge 

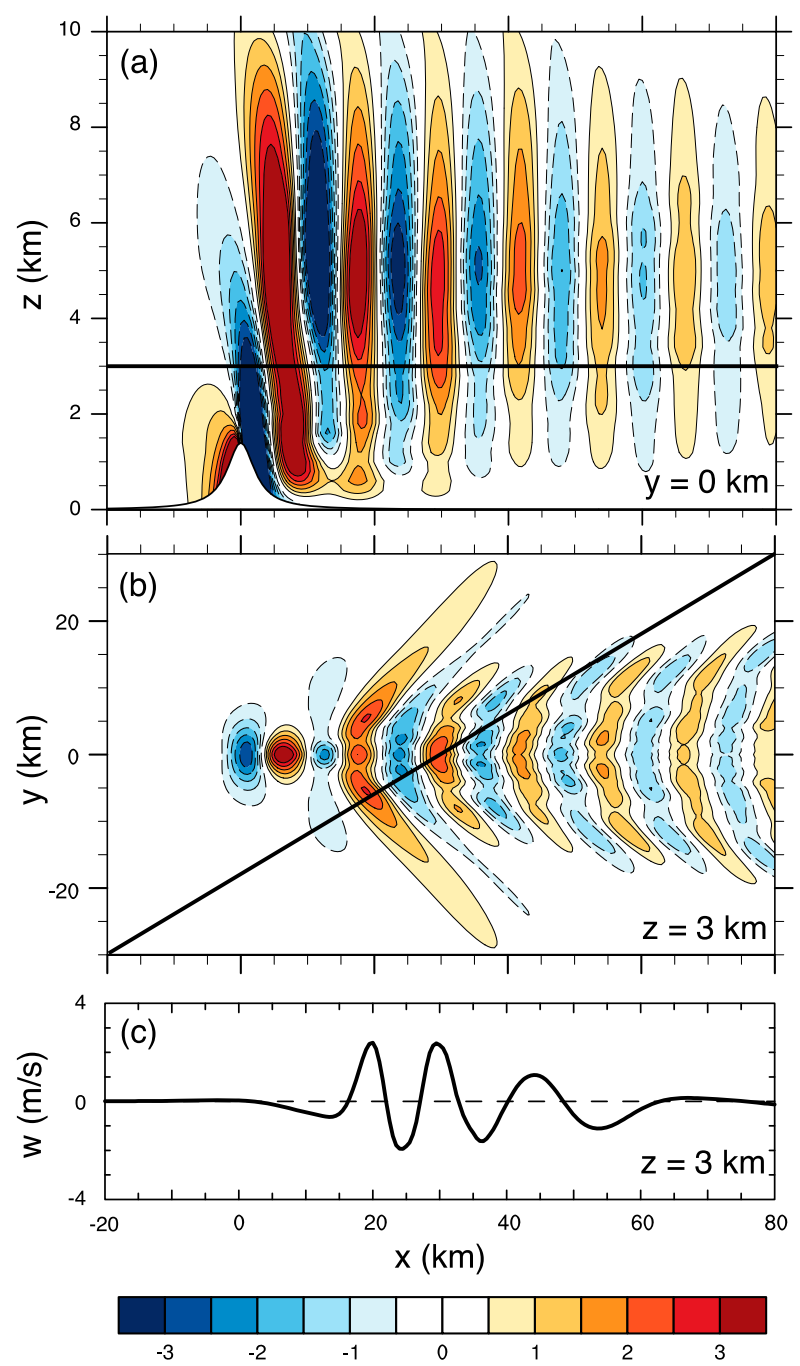

FIG. 12. Steady nonlinear vertical velocity for idealized lee-wave simulation for flow over a 3D $1300 \mathrm{~m}$ circular bell-shaped mountain, with temperature and wind profiles corresponding to the 1200 UTC sounding from Keflavik (Fig. 3). (a) Vertical cross section of vertical velocity along the centerline of the wave train, (b) horizontal cross section of vertical velocity at $z=3 \mathrm{~km}$, and (c) vertical velocity profile at $z=3 \mathrm{~km}$ taken approximately along the aircraft track that traversed the waves downstream of the mountain.

having a bell-shaped profile as defined in (1), which has a simple closed form for its Fourier transform:

$$
\hat{h}(k)=\pi a H e^{-|k| x} .
$$

We then analyze the linear wave structure in terms of the Fourier components of the displacement height $\hat{\delta}$, where

$$
\hat{\delta}(k, z)=\int_{-\infty}^{\infty} \delta(x, z) e^{-i k x} d x
$$

For a shallow atmosphere, the 2D linear inviscid steadystate wave equation for layers of constant wind and stability can be represented as

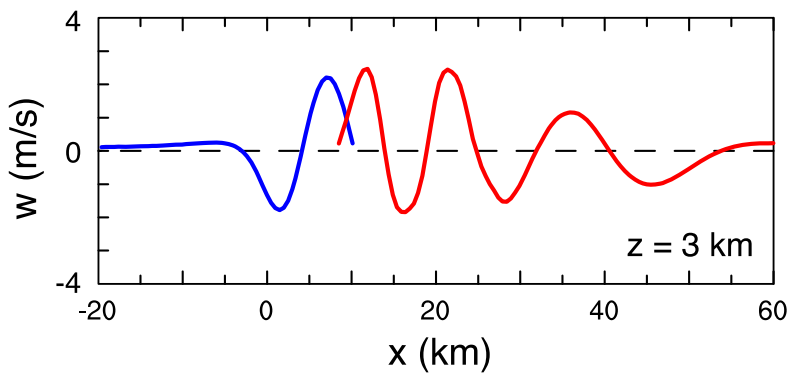

FIG. 13. Possible combined vertical velocity profile for the $2 \mathrm{D}$ ridge (Fig. 11b) and the 3D isolated mountain (Fig. 12c) at $z=3 \mathrm{~km}$ taken approximately along the aircraft track that traversed downstream of the mountain. The upstream (left) portion of the profile represents the $2 \mathrm{D}$ response over the ridge while the downstream (right) portion is taken from the location of the aircraft track behind the isolated mountain.

$$
\frac{\partial^{2} \hat{\delta}}{\partial z^{2}}+\left(\frac{N^{2}}{U^{2}}-k^{2}\right) \hat{\delta}=0 .
$$

We apply this equation both throughout the stable layer above the inversion and within the neutral boundary (with $N=0)$ subject to the free-slip lower boundary condition $\hat{\delta}(k, 0)=\hat{h}(k)$. The matching conditions across the inversion separating the two layers require continuity of the displacement height and the pressure across the interface (Klemp and Lilly 1975). Including the jump in potential temperature across the inversion these matching conditions require

$$
\hat{\delta}_{1}=\hat{\delta}_{2} \quad \text { and } \quad \frac{\partial \hat{\delta}_{1}}{\partial z}-\frac{g^{\prime}}{U^{2}} \hat{\delta}_{1}=\frac{\partial \hat{\delta}_{2}}{\partial z} \quad \text { at } \quad z=z_{i}
$$

where the subscripts 1 and 2 refer to the lower and upper layers, respectively, and $g^{\prime}=\left(\Delta \theta / \theta_{0}\right) g$ is the reduced gravity.

\section{b. Fourier modes of the linear solution}

Accommodating the lower boundary condition, the solutions to (4) within each layer have the following form:

$$
\begin{aligned}
& \hat{\delta}_{1}=\hat{h}(k)\left(\cosh k z+C_{1} \sinh k z\right), \\
& \hat{\delta}_{2}=\hat{h}(k) C_{2}\left\{\begin{array}{ccc}
e^{-i \operatorname{sgn}(k) l\left(z-z_{i}\right)} & \text { for } & l^{2}=\frac{N^{2}}{U^{2}}-k^{2}>0 \\
e^{-\mu\left(z-z_{i}\right)} & \text { for } \quad \mu^{2}=k^{2}-\frac{N^{2}}{U^{2}}>0
\end{array}\right.
\end{aligned}
$$

Here, the solution for $\hat{\delta}_{2}$ for $l^{2}>0$ employs a radiation condition that ensures upward-propagating wave energy, while for $\mu^{2}>0$ the waves are evanescent. Applying the matching conditions (5) at $z=z_{i}$, we obtain

$$
\begin{aligned}
& C_{2}=\cosh k z_{i}+C_{1} \sinh k z_{i}, \\
& C_{1}=\frac{F^{2} k z_{i} \tanh k z_{i}-1}{\tanh k z_{i}-F^{2} k z_{i}},
\end{aligned}
$$

where 


$$
F^{2}=\left\{\begin{array}{ll}
{\left[\frac{g^{\prime} z_{i}}{U^{2}}-i \operatorname{sgn}(k) l z_{i}\right]^{-1}} & \text { for } \quad l^{2}>0 \\
\left(\frac{g^{\prime} z_{i}}{U^{2}}-\mu z_{i}\right)^{-1} & \text { for } \mu^{2}>0
\end{array} .\right.
$$

If the Fourier displacements $\hat{\delta}_{i}$ are analytic, the full linear wave solution is obtained by using (6)-(9) to numerically integrate the inverse Fourier transform:

$$
\delta_{i}(x, z)=\frac{1}{2 \pi} \int_{-\infty}^{\infty} \hat{\delta}_{i}(k, z) e^{i k x} d k
$$

\section{c. Trapped resonant wave solution}

If the expression for $\hat{\delta}_{i}$ is singular for certain values of $k=k_{s}$, the linear solution may contain trapped resonant modes in addition to the forced vertically propagating and evanescent modes. These singularities arise for values of $k$ where the denominator of $C_{1}$ in (8) goes to zero. As recognized by Vosper (2004), these trapped modes can occur only at wavenumbers that are evanescent above the inversion $\left(\mu^{2}>0\right)$. Otherwise the modes would propagate vertically above the inversion and not be trapped in the lower layer. Thus, resonant modes occur at wavenumbers $k_{s}$ that satisfy

$$
\tanh k_{s} z_{i}=F_{s}^{2} k_{s} z_{i}
$$

where $F_{s}$ is given by (9) for $\mu^{2}=\mu_{s}^{2}=k_{s}^{2}-(N / U)^{2} \geq 0$. By trapping the energy in these resonant modes within the lower layer, they form a periodic wave train that can persist indefinitely far downstream of the terrain. As pointed out by Vosper (2004), the requirement that $\left|k_{s}\right| \geq N / U$ for the existence of resonant waves establishes a lower bound on the Froude number, $F_{r}^{2}=U^{2} /\left(g^{\prime} z_{i}\right)$ [by setting $k_{s}=N / U$ in (11)], which defines the threshold height

$$
z_{i} \geq \frac{U}{N} \operatorname{arctanh}\left(\frac{N U}{g^{\prime}}\right)
$$

for resonant waves to occur.

For a simple pole at $k=k_{s}$, the function

$$
f\left(k_{s}\right)=\left(k-k_{s}\right) z_{i} C_{1}
$$

will be analytic and can be used to calculate the resonant mode as a residue using Cauchy's integral formula. This function is also needed to remove the singularity from the inverse transform integral (10) such that the vertically propagating contributions to the full linear wave solution can be computed. The function $f\left(k_{s}\right)$ is readily obtained by expanding $C_{1}$ in a Taylor series about $k=k_{s}$ and taking the limit as $k \rightarrow k_{s}$ :

$$
f\left(k_{s}\right)=\left[F_{s}^{2}\left(1+\frac{k_{s}}{\mu_{s}} \tanh k_{s} z_{i}\right) \cosh ^{2} k_{s} z_{i}-1\right]^{-1} .
$$

To this point our analysis parallels the derivation by Vosper (2004) for the resonant lee waves. With the poles in (14) located on the real $k$ axis, formal contour integration as described by Scorer (1949) and Sawyer (1960) leads to a displacement amplitude for resonant mode $\delta_{r_{i}}$ contained in (10) that is $\pi i$ (not the desired $2 \pi i)^{1}$ times the sum of the complex conjugate residues at $k= \pm k_{s}$ :

$$
\begin{gathered}
\delta_{r_{i}}(x, z)=i R\left(k_{s}, z\right) e^{-k_{s} x}+\text { complex conjugate, } \\
=\left\{\begin{array}{cl}
-R\left(k_{s}, z\right) \sin k_{s} x & \text { for } \quad x \geq 0 \\
R\left(k_{s}, z\right) \sin k_{s} x & \text { for } \quad x<0
\end{array}\right.
\end{gathered}
$$

where

$$
R\left(k_{s}, z\right)=\frac{1}{z_{i}} \hat{h}\left(k_{s}\right) f\left(k_{s}\right)\left\{\begin{array}{ccc}
\sinh \left(k_{s} z\right) & \text { for } & z<z_{i} \\
\sinh \left(k_{s} z_{i}\right) e^{-\mu\left(z-z_{i}\right)} & \text { for } & z>z_{i}
\end{array}\right.
$$

Notice that this integration for the resonant mode yields an amplitude that does not vanish far upstream of the mountain. This arises because, as discussed by Lamb (1945), the inviscid linear steady solution has an indeterminacy in that one can superimpose a train of stationary waves of arbitrary amplitude and still satisfy the linear equation. Since $\hat{\delta}_{i} \rightarrow \pm \infty$ at $k= \pm k_{s}$, a Dirac delta function $D\left( \pm k_{s}\right)$ can be added to $\hat{\delta}_{i}$ without altering its value. Including a delta function in the inverse transform (10) adds a periodic wave to the solution at the resonant wavelength $k_{s}$. This indeterminacy has been removed by Scorer (1949), Sawyer (1960), and others by recognizing the wave amplitude must vanish far upstream of the mountain and adjusting the resonant wave amplitude to achieve that result. With this approach, we subtract $R\left(k_{s}, z\right) \sin k_{s} x$ from the expression in (16) and recover the same result as obtained by Vosper (2004):

$$
\delta_{r_{i}}(x, z)=\left\{\begin{array}{ccc}
-2 R\left(k_{s}, z\right) \sin k_{s} x & \text { for } & x \geq 0 \\
0 & \text { for } & x<0
\end{array} .\right.
$$

Lamb (1945) points out that this indeterminacy in the resonant wave amplitude can be removed by including a vanishingly small amount of viscosity in the steady linear analysis, as proposed by Rayleigh (1883). This small viscosity moves the pole slightly above the real $k$ axis, allowing the pole to be completely inside (or outside) the closed contour that includes the real $k$ axis. Lighthill (1978) addressed this ambiguity by including a small exponential growth in the disturbances that would be consistent with the waves having grown slowly from an initially undisturbed state. This approach also moves the poles slightly off the real $k$ axis and produces the desired behavior far upstream of the obstacle.

\section{d. Full linear wave solution}

To obtain the full steady linear wave solution for this twolayer atmosphere, we extend Vosper's (2004) analysis to include the forced vertically propagating modes in addition to the trapped resonant modes. To this end, we integrate (10) following the procedure utilized by Sawyer (1960) in which the

\footnotetext{
${ }^{1}$ With a pole on the real axis, contour integration over a path that encloses the pole by deviating in a small semicircle around the pole contributes only $\pi i$ times the residue rather than $2 \pi i$.
} 
singularities in the integrand of (10) are removed in a manner that allows the forced and resonant contributions to the solution to be computed separately. For this purpose, we note that the form of $\hat{\delta}_{i}$ in the limit as $k$ approaches the two singularities at $k= \pm k_{s}$ is simply

$$
\lim _{k \rightarrow \pm k_{s}} \hat{\delta}_{i}(k, z)=\frac{ \pm R\left(k_{s}, z\right)}{k \mp k_{s}} .
$$

To remove the singularities at the poles, we add and subtract the asymptotic limit of $\hat{\delta}_{i}$ near each pole, with the result that (10) becomes

$$
\begin{aligned}
\delta_{i}(x, z)= & \frac{1}{2 \pi} \int_{-\infty}^{\infty}\left\{\hat{\delta}_{i}(k, z)-R\left(k_{s}, z\right)\left[\frac{1}{k-k_{s}}-\frac{1}{k+k_{s}}\right]\right\} e^{i k x} d k \\
& +\frac{R\left(k_{s}, z\right)}{2 \pi}\left\{\int_{-\infty}^{\infty} \frac{e^{i k x}}{k-k_{s}} d k-\int_{-\infty}^{\infty} \frac{e^{i k x}}{k+k_{s}} d k\right\} .
\end{aligned}
$$

Here, the first integral represents the forced mode and can be evaluated numerically by integrating along the real $k$ axis since the integrand is now analytic, having removed the singular behavior near the poles. The integrals on the second line in (20) represent the resonant modes for $k= \pm k_{s}$ and can be integrated directly (Gradshteyn and Ryzhik 1965) to yield the same result as (16). This solution contains the same ambiguity (finite amplitude far upstream) as discussed above when the poles reside on the real $k$ axis, and is similarly removed to achieve the full solution:

$$
\delta_{i}(x, z)=\frac{1}{2 \pi} \int_{-\infty}^{\infty}\left\{\hat{\delta}_{i}(k, z)-\frac{2 k_{s} R\left(k_{s}, z\right)}{k^{2}-k_{s}^{2}}\right\} e^{i k x} d k+\delta_{r_{i}}(x, z),
$$

where $\delta_{r_{i}}(x, z)$ is given by (18).

\section{e. Influence of inversion layer on linear wave structure}

In evaluating the structure of lee waves from the perspective of steady-state linear theory, it is important to consider contributions from both the trapped resonant modes (if present) and the forced vertically propagating modes. This is illustrated in an idealized case for an atmosphere characterized by a constant mean wind $U=20 \mathrm{~m} \mathrm{~s}^{-1}$, a constant stability $N=$ $0.01 \mathrm{~s}^{-1}$ above a neutrally stable boundary layer with $\theta_{0}=$ $273 \mathrm{~K}$ capped by an inversion of strength $\Delta \theta=10 \mathrm{~K}$. The bellshaped terrain is specified as in (1) with height $H=500 \mathrm{~m}$ and half-width $a=2.5 \mathrm{~km}$, which are reasonable approximations for the ridge of the Snæfellsnes Peninsula. For this case, the critical inversion height, represented by the equal sign in (12), occurs at $z_{i}=1317 \mathrm{~m}$, which corresponds to a Froude number of $F_{r}^{2}=0.877$. Figure 14 displays the full vertical velocity (21) together with the contribution from the trapped resonance mode (18) for an inversion height $z_{i}=1300 \mathrm{~m}$ just below the critical height and for two heights (1500 and $1700 \mathrm{~m})$ above the critical value. Notice that for $z_{i}=1300 \mathrm{~m}$ (Fig. 14a), there is a strong wave train extending far downstream of the mountain even though there is no resonant mode at this inversion height. This wave train is similar in the lower-midtroposphere to the vertical cross sections for $w$ in the E1 WRF simulation shown in Figs. 7 and 8, with a horizontal wavelength of just under $13 \mathrm{~km}$. One notable difference is that the amplitudes of the waves in the full WRF simulation decrease in the upper troposphere and are nearly absent in the stratosphere (Fig. 7). In contrast, the forced mode in Fig. 14a does not diminish at upper levels because this simple two-layer atmosphere does not contain additional structure in the mid- to upper troposphere that may induce partial trapping of the waves, as discussed in the next section.

The behavior evident in Fig. 14 contrasts sharply from wave structure that arises in the absence of the inversion layer, as illustrated in Fig. 15 for the case of $z_{i}=0$. For this single layer solution, $C_{2}=1$ in (7) and individual wavenumbers have amplitudes consistent with the terrain forcing $\hat{h}(k)$. The wave energy for each wavenumber propagates upward and downstream at angle:

$$
\phi=\arctan \left(\frac{c_{g z}}{c_{g x}}\right)=\arctan \left[\left(\frac{N^{2}}{k^{2} U^{2}}-1\right)^{1 / 2}\right]
$$

with respect to the horizontal, as discussed by Klemp and Lilly (1980). Here $c_{g x}$ and $c_{g z}$ represent the horizontal and vertical group velocities, respectively. Thus, the wave train in Fig. 15 has little amplitude at low levels downstream of the mountain. The wave energy propagates nearly vertically above the mountain, extending somewhat downstream with increasing height due to nonhydrostatic influences on the wave propagation. This wave structure is similar to that obtained in Vosper's (2004, Fig. 3) numerical lee-wave simulation for $z_{i}=0$.

As the inversion height is increased toward its critical value, the coefficient $C_{1}$ in (6)-(8) increases in magnitude as its denominator moves toward the singularity that is realized at the critical depth. This increase in amplitude has a sharp maximum at wavenumbers just slightly smaller than the resonant wavenumber $k_{s}=N / U$. As evident in Fig. $14 \mathrm{a}$, for $z_{i}=1300 \mathrm{~m}$ the wave train at the inversion level has significant amplitude that extends far downstream of the terrain. Although these waves are not resonant, since their wavenumber is only slightly smaller than $N / U$, their wave energy propagates upward at a very shallow angle as indicated by (22).

As the inversion height is increased above the critical value, the amplitude of the resonant mode increases, reaching a maximum vertical velocity of $2.09 \mathrm{~m} \mathrm{~s}^{-1}$ for $z_{i}=1500 \mathrm{~m}$ (Fig. 14d) and $2.91 \mathrm{~m} \mathrm{~s}^{-1}$ at $z_{i}=1700$ (Fig. 14f). Further increasing $z_{i}$, the resonant amplitude reaches a maximum of $3.05 \mathrm{~m} \mathrm{~s}^{-1}$ at $z_{i} \simeq 1900 \mathrm{~m}$ and then decreases at larger depths. However, with increasing $z_{i}$ above the critical height, the magnitudes of the vertically propagating modes are decreasing as the resonant amplitude is increasing, such that the combined amplitudes are changing only very gradually. The most noticeable variation in the wave train as the inversion height is increased above its critical depth, is a lowering of the location of the maximum vertical velocity (at $z_{i}=1900 \mathrm{~m}$ the maximum vertical velocity is at the inversion level). Consequently, we emphasize that in utilizing linear theory to evaluate the 

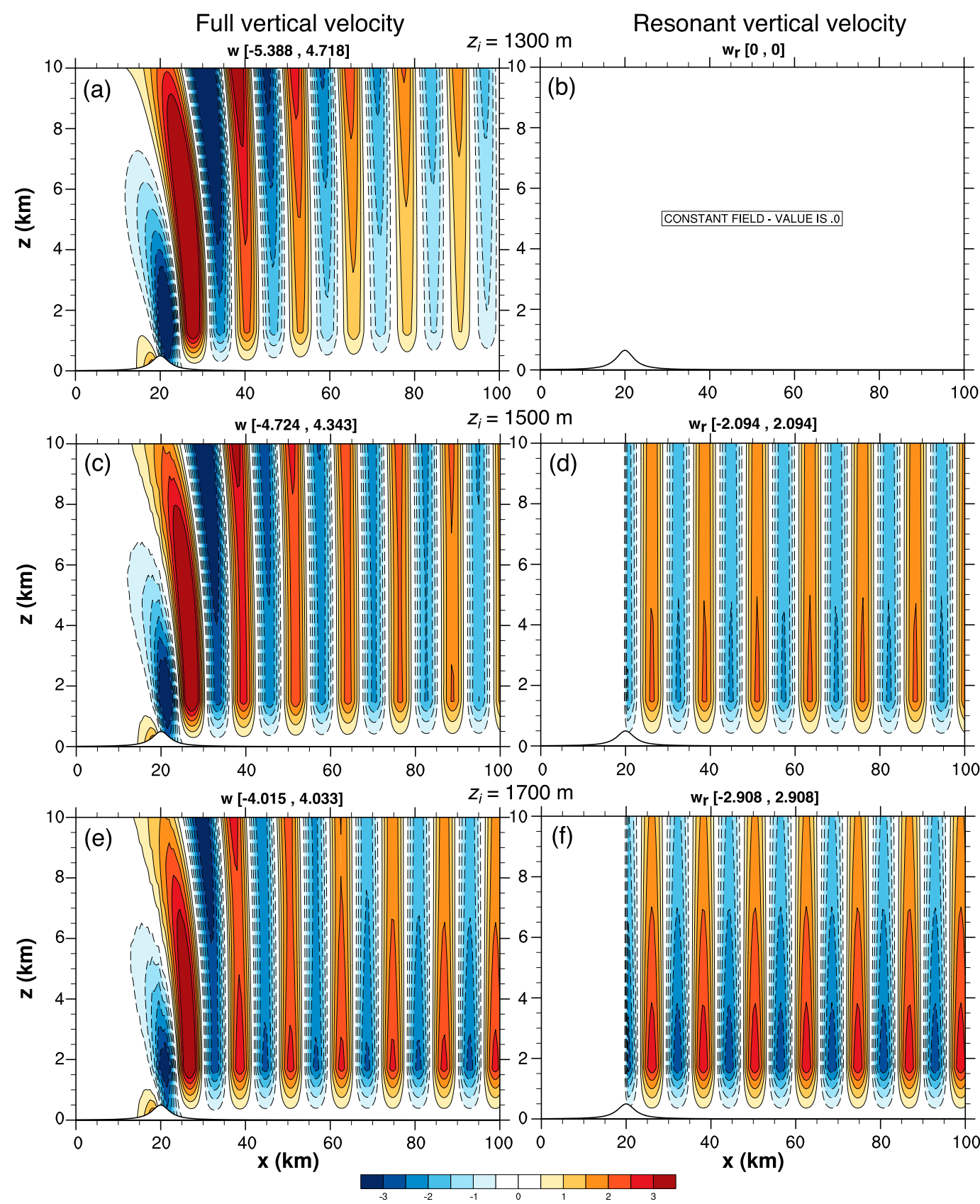

FIG. 14. Steady linear analytic vertical velocity for an atmosphere having constant mean wind $U=20 \mathrm{~m} \mathrm{~s}^{-1}$ and stability $N=0.01 \mathrm{~s}^{-1}$ above a neutral boundary layer of depth $z_{i}$ equal to (a),(b) 1300; (c),(d) 1500; and (e),(f) $1700 \mathrm{~m}$, beneath a $10 \mathrm{~K}$ capping inversion. (a),(c),(e) Full vertical velocity and (d),(d),(f) resonant mode vertical velocity. Here, the critical depth for resonant modes to exist is $z_{i}=1317 \mathrm{~m}$.

characteristics of lee waves, it is important to consider the full linear solution in addition to the resonant modes, since the vertically propagating modes may contribute significantly to (or even dominate) the behavior of these waves.

In the WRF Model simulations of the Snæfellsnes lee waves, while the wave train extends far downstream of the peninsula, the waves have maximum amplitudes in the midtroposphere, well above the height of the low-level inversion (see Fig. 7)
Thus it is likely that these waves are not resonant modes trapped by this inversion, but rather are vertically propagating modes above this level, excited at horizontal scales slightly smaller than the resonant wavelength supported by this inversion. However, Fig. 7 indicates that these waves have little amplitude above the troposphere, suggesting that there may be a partial trapping of wave energy within the troposphere. 


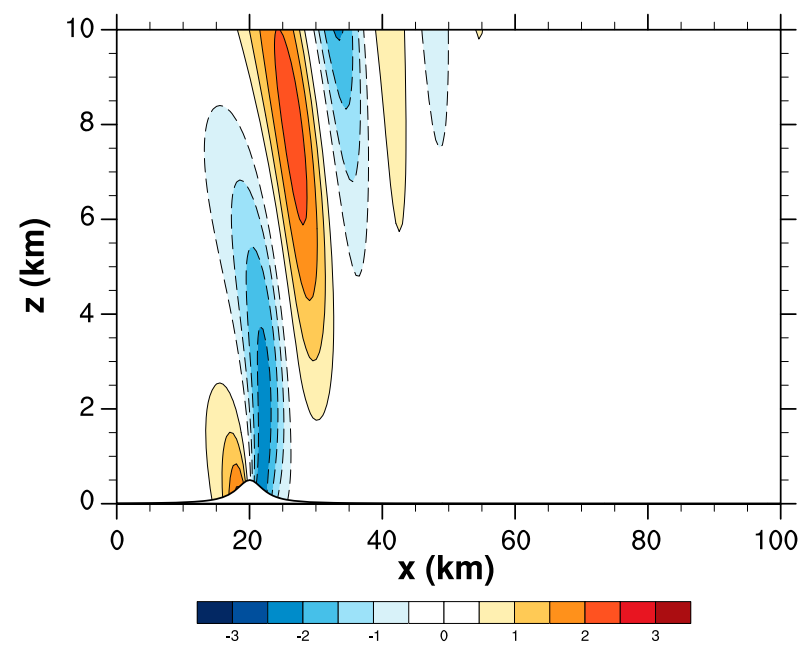

FIG. 15. Steady linear vertical velocity for a single-layer atmosphere with $U=20 \mathrm{~m} \mathrm{~s}^{-1}$ and $N=0.01 \mathrm{~s}^{-1}$.

\section{Near-resonant modes in the midtroposphere}

Above the boundary layer inversion, there is a layer of enhanced tropospheric stability between about 620 and $500 \mathrm{hPa}$, with reduced stability between this layer and the tropopause at about $230 \mathrm{hPa}$ (see Fig. 3). Consequently, there may be a partial resonance of specific modes that are trapped in the lower-midtroposphere. This can be demonstrated through an eigenfunction analysis by vertically integrating the TaylorGoldstein Eq. (4) to find the horizontal wavenumber $k$ that yields nontrivial solutions to this equation subject to the boundary condition $\hat{w}=0$ at $z=0$, and a radiation condition in the stratosphere that permits upward propagation of wave energy. This eigenfunction analysis is similar to that utilized by Durran et al. (2015), who investigated the characteristics of leaky trapped mountain waves that arise due to the presence of a stable stratosphere. Because some wave energy penetrates into the stratosphere, a nontrivial solution to this eigenvalue problem can only exist for complex $k$. If the amplitude of the waves leaking through the upper boundary is small compared to the maximum amplitude below and the imaginary part of $k$ is small compared to the real part, this near-resonant mode will produce a wave train that decays slowly downstream.

We have applied this eigenfunction analysis to the Snæfellsnes lee waves by defining the mean wind $U$ and stability $N$ based on the Keflavík sounding as shown in Fig. 3. For this analysis, we have simplified the stratospheric conditions to a constant $\lambda=$ $N / U=0.001 \mathrm{~m}^{-1}$ above $z=12 \mathrm{~km}$. An upper radiation boundary condition $\partial \hat{w} / \partial z=i \sqrt{\lambda^{2}-k^{2}} \hat{w}$ is then applied at the upper boundary for the numerical integration at $z=20 \mathrm{~km}$. The eigenvalue problem is solved numerically using secondorder accurate finite differencing of (4) subject to the boundary conditions mentioned above by iterating on the wavenumber $k$ until the determinant of the discretized system is zero. The eigenvalue solution for this sounding does in fact support a near-resonant mode in the midtroposphere, as shown in Fig. 16. The wavelength is $12.5 \mathrm{~km}$ (blue dashed line in Fig. 16), which is consistent with the idealized 2D wave structure in
Fig. 11. The wave has a vertically propagating character within the low-level inversion and within the stable layer between 3.7 and $5.5 \mathrm{~km}$, and is evanescent in the upper troposphere. The wave amplitude is less than $20 \%$ of its peak value by the time it reaches the stratosphere, where it resumes a vertically propagating character with periodic phase change with height. The ratio of real to imaginary parts of the wavenumber, $k_{r} / k_{i}$ is 105 , representing an $e$-folding distance for downwind decay of the wave of $210 \mathrm{~km}$ or 16 wavelengths. We note that although this eigenfunction analysis identifies the horizontal scale and vertical structure of the near-resonant mode, it does not provide any information on the amplitude of the response or the contributions of forced modes to the overall wave structure. Nevertheless, these results appear to be consistent with the full 2D lee-wave simulation shown in Fig. 11. Together with those in the previous section, the results suggest how near-resonant forced modes, amplified by the low-level inversion, are partially trapped in the midtroposphere.

\section{Summary}

The aircraft observations of lee waves over the Snæfellsnes Peninsula, Iceland, on 20 October 2016 have provided a unique opportunity to investigate the dynamics of mountain waves produced by this interesting orography. The aircraft observations, along with an upwind radiosonde profile from Keflavík Airport and satellite imagery revealed an upwind atmospheric profile with a strong boundary layer capping inversion between 1300 and $1400 \mathrm{~m}$ altitude, and clear evidence of separate gravity wave trains from the Snæfellsnes Peninsula and the Sæfellsjökull volcano at the end of the peninsula, with horizontal wavelengths approximately $12.5 \mathrm{~km}$ and peak-to-peak amplitudes of over $\pm 4 \mathrm{~m} \mathrm{~s}^{-1}$.

We have shown that numerical simulations with the WRF Model are consistent with the aircraft observations and provide a broader perspective of the overall wave train that formed in the lee of the peninsula and volcano. Comparison between the aircraft measurements and the WRF simulations along the flight track confirm that there was a combination of influences from the two distinct orographic features. In traversing the peninsula from south to north, the aircraft first encountered the lee waves behind the ridge and then rapidly crossed into the wave train produced by the volcano. The simulated and observed vertical velocities along the flight tracks are in overall good agreement, both in terms of wave amplitude and wavelength with the observed vertical velocities. By separately simulating the response to the peninsula and the volcano and then combining the resulting waves, we have been able to demonstrate that the total wave field can be accurately reconstructed from simply combining the wave trains produced by these individual orographic features, demonstrating consistency with a linear combination of the lee waves.

Further insight into the wave dynamics has been provided by idealized simulations for 2D flow over a ridge and $3 \mathrm{D}$ flow past an isolated mountain, supplying further evidence that the observed wave train in the lee of the Snæfellsnes Peninsula and Snæfellsjökull volcano can be well represented by the individual contributions from the two distinct terrain features. 

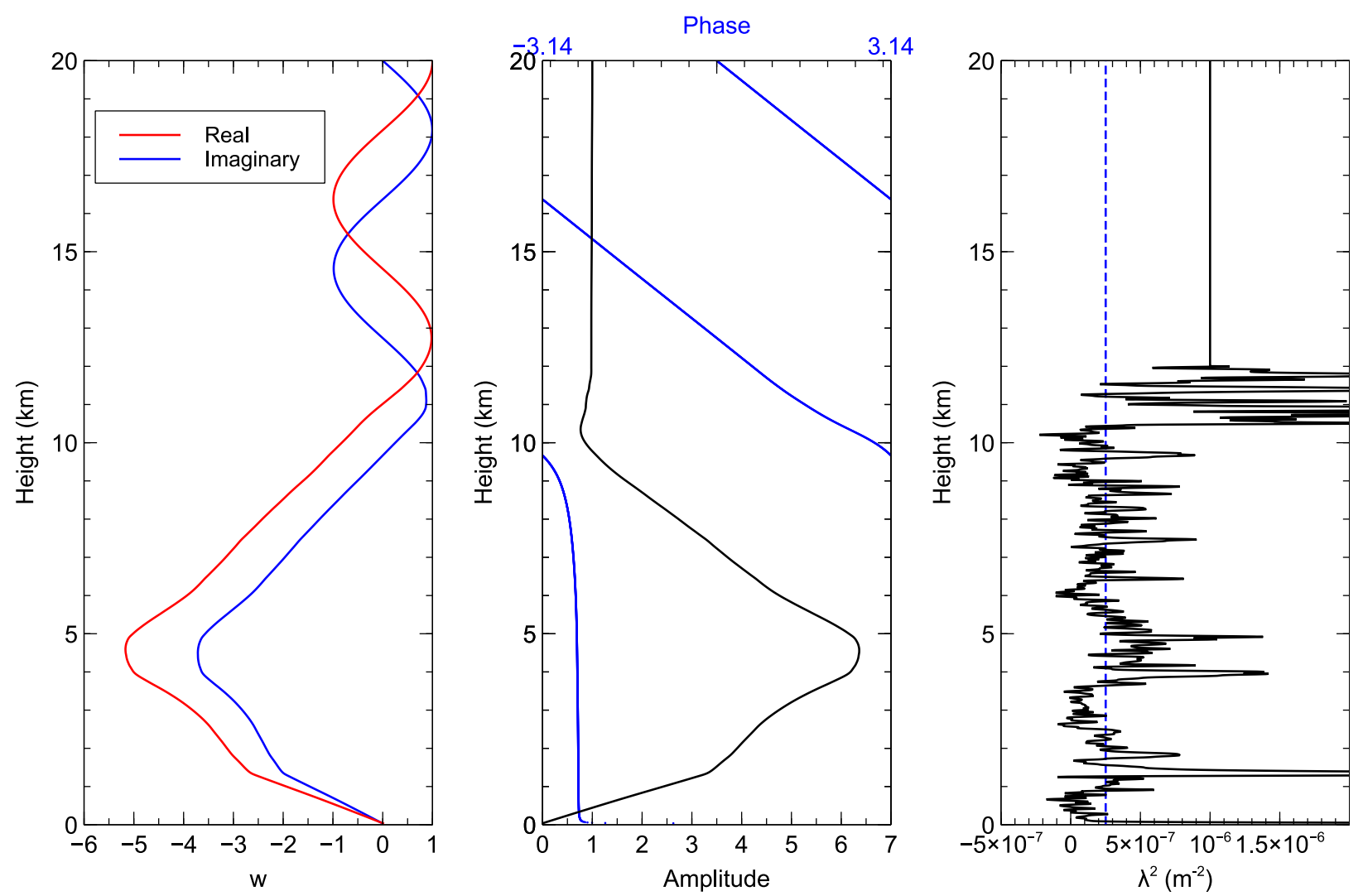

FIG. 16. (left) Real and imaginary parts of the eigenfunction $\hat{w}$ (arbitrary units). (center) Amplitude and phase of the eigenfunction $\hat{w}$ (arbitrary units). (right) $\lambda^{2}$ for the modified sounding including an idealized stratosphere used to solve Eq. (4). The blue dashed line shows the wavenumber.

The observed presence of a periodic wave train extending far downstream of the forcing terrain (for at least seven wavelengths in the satellite imagery) suggests these waves might be resonant waves whose wave energy is trapped below a strong inversion at the top of the boundary layer. However, the wave structures in the WRF and idealized simulations reveal maximum wave amplitudes in the midtroposphere without the appearance of local maxima in the vicinity of the inversion capping the PBL. Our linear analytic analysis of both the trapped and vertically propagating modes indicate that in the absence of resonant modes produced by the low-level inversion, vertically propagating modes that are close to the resonant wavelength can have significant amplitude and extend far downstream because their vertical group velocity is very small. In addition, a linear eigenvalue calculation demonstrates that the observed environmental sounding also supports nearresonant waves in the midtroposphere. The vertically propagating waves that we identify in the linear analytic analysis for the low-level inversion potentially provide a mechanism for forcing these near-resonant waves aloft.

The actual lee waves forming over this Icelandic peninsula contain inherent complexity due to influences such as nonlinearities, horizontal inhomogeneities, and evolving forcing conditions. Unfortunately, the limited available observations in both time and space complicate our ability to analyze these more subtle interactions that modulate the lee-wave structure. Nevertheless, we believe the application of linear theory for simplified atmospheric environments provides useful guidance in understanding the basic mechanisms that produce these more complex wave trains.

Our ability to realistically represent the processes governing gravity wave flows over mountains in both weather and climate models has been hampered by the paucity of observations, the formidable challenge of understanding the influences of these waves on larger scales of motion, and the representation of these processes in models. In this context, our study addresses a novel set of lee-wave observations and uses a hierarchy of models to shed new light on the dynamical mechanisms generating these waves and their dependence on the larger-scale environment. These findings will help to better define orographic gravity wave forcing functions on a physical basis, which is required to enhance orographic gravity wave forcing, which has been shown to help alleviate the Southern Hemisphere cold-pole bias in many climate models. Such an approach may also be helpful in achieving a more holistic understanding of these dynamics, in developing more physically based approaches for parameterizing orographic influences in weather and climate models, and in identifying directions for further improvement of observational instrumentation and observing methodologies. 
Acknowledgments. This study was supported by U.K. Natural Environment Research Council Grant NE/I015612/1. The National Center for Atmospheric Research (NCAR) is supported by the National Science Foundation. We thank all of the the Facility for Airborne Atmospheric Measurements (FAAM) staff and the aircraft operator Airtask Ltd as well as the pilots Finbarre Brennan and Steven Jones for making the flight possible. We thank Haraldur Ólafsson at the University of Iceland for discussion and helpful comments at the initial stages of this work. The simulations were performed on resources provided by the Archer U.K. National Supercomputing Service, on NCAR computers in the United States, and on the data-cluster Achray at the University of Edinburgh.

\section{REFERENCES}

Abernethy, J., 2008: A domain-analysis approach to clear-air turbulence forecasting using high-density in-situ measurements. $\mathrm{Ph} . \mathrm{D}$. thesis, University of Colorado, $152 \mathrm{pp}$.

Agústsson, H., and H. Olafsson, 2009: Forecasting wind gusts in complex terrain. Meteor. Atmos. Phys., 103, 173-185, https:// doi.org/10.1007/s00703-008-0347-y.

— turbulence. Mon. Wea. Rev., 142, 832-849, https://doi.org/ 10.1175/MWR-D-13-00212.1.

Bramberger, M., A. Dörnbrack, H. Wilms, F. Ewald, and R. Sharman, 2020: Mountain-wave turbulence encounter of the research aircraft HALO above Iceland. J. Appl. Meteor. Climatol., 59, 567-588, https://doi.org/10.1175/JAMC-D-19-0079.1.

Doyle, J. D., and D. R. Durran, 2002: The dynamics of mountain-wave-induced rotors. J. Atmos. Sci., 59, 186-201, https://doi.org/10.1175/1520-0469(2002)059<0186:TDOMWI> 2.0.CO;2.

Dudhia, J., 1989: Numerical study of convection observed during the Winter Monsoon Experiment using a mesoscale two-dimensional model. J. Atmos. Sci., 46, 3077-3107, https://doi.org/ 10.1175/1520-0469(1989)046<3077:NSOCOD>2.0.CO;2.

Durran, D. R., 1986: Another look at downslope windstorms. Part I-The development of analogs to supercritical flow in an infinitely deep, continuously stratified fluid. J. Atmos. Sci., 43, 2527-2543, https://doi.org/10.1175/1520-0469(1986)043<2527: ALADWP $>2.0 . \mathrm{CO} ; 2$.

— M. O. G. Hills, and P. N. Blossey, 2015: The dissipation of trapped lee waves. Part I: Leakage of inviscid waves into the stratosphere. J. Atmos. Sci., 72, 1569-1584, https://doi.org/ 10.1175/JAS-D-14-0238.1.

Flamant, C., E. Richard, C. Schär, R. Rotunno, L. Nance, M. Sprenger, and R. Benoit, 2004: The wake south of the Alps: Dynamics and structure of the lee-side flow and secondary potential vorticity banners. Quart. J. Roy. Meteor. Soc., 130, 1275-1303, https://doi.org/10.1256/qj.03.17.

Fritts, D. C., and Coauthors, 2016: The Deep Propagating Gravity Wave Experiment (DEEPWAVE): An airborne and groundbased exploration of gravity wave propagation and effects from their sources through the lower and middle atmosphere. Bull. Amer. Meteor. Soc., 97, 425-453, https://doi.org/10.1175/ BAMS-D-14-00269.1.

Gradshteyn, I. S., and I. M. Ryzhik, 1965: Table of Integrals, Series, and Products. Academic Press, 406 pp.

Grubišić, V., and Coauthors, 2008: The Terrain-Induced Rotor Experiment: A field campaign overview including observa- tional highlights. Bull. Amer. Meteor. Soc., 89, 1513-1534, https://doi.org/10.1175/2008BAMS2487.1.

Jackson, D. R., and Coauthors, 2018: The South Georgia Wave Experiment (SG-WEX)?A means for improving analysis of gravity waves and low-level wind impacts generated from mountainous islands. Bull. Amer. Meteor. Soc., 99, 1027-1040, https://doi.org/10.1175/BAMS-D-16-0151.1.

Janjić, Z. I., 1994: The step-mountain Eta coordinate model: Further developments of the convection, viscous sublayer, and turbulence closure schemes. Mon. Wea. Rev., 122, 927-945, https://doi.org/10.1175/1520-0493(1994)122<0927:TSMECM> 2.0.CO;2.

Jiang, Q. F., and J. D. Doyle, 2005: Wave breaking induced surface wakes and jets observed during a bora event. Geophys. Res. Lett., 32, L17807, https://doi.org/10.1029/2005GL022398.

Kain, J. S., 2004: The Kain-Fritsch convective parameterization: An update. J. Appl. Meteor., 43, 170-181, https://doi.org/ 10.1175/1520-0450(2004)043<0170:TKCPAU>2.0.CO;2.

Klemp, J. B., and D. K. Lilly, 1975: Dynamics of wave-induced downslope winds. J. Atmos. Sci., 32, 320-339, https://doi.org/ 10.1175/1520-0469(1975)032<0320:TDOWID>2.0.CO;2.

, and —, 1980: Mountain waves and momentum flux. Orographic Effects in Planetary Flows, Vol. 23, GARP Publication Series, 115-141.

, W. C. Skamarock, and J. Dudhia, 2007: Conservative splitexplicit time integration methods for the compressible nonhydrostatic equations. Mon. Wea. Rev., 135, 2897-2913, https:// doi.org/10.1175/MWR3440.1.

- J. Dudhia, and A. Hassiotis, 2008: An upper gravity-wave absorbing layer for NWP applications. Mon. Wea. Rev., 136, 3987-4004, https://doi.org/10.1175/2008MWR2596.1.

Lamb, H., 1945: Hydrodynamics. 6th ed. Dover Publications, 399 pp.

Lighthill, J., 1978: Waves in Fluids. Cambridge University Press, $267 \mathrm{pp}$.

Lilly, D. K., 1972: Wave momentum flux: The GARP problem. Bull. Amer. Meteor. Soc., 53, 17-24, https://doi.org/10.1175/ 1520-0477-53.1.17.

_- 1978: A severe downslope windstorm and aircraft turbulence event induced by a mountain wave. J. Atmos. Sci., 35, 59-77, https://doi.org/10.1175/1520-0469(1978) 035<0059:ASDWAA $>2.0 . \mathrm{CO} ; 2$.

Mlawer, E. J., S. J. Taubman, P. D. Brown, M. J. Iacono, and S. A. Clough, 1997: Radiative transfer for inhomogeneous atmospheres: RRTM, a validated correlated-k model for the longwave. J. Geophys. Res., 102, 16 663-16 682, https://doi.org/ 10.1029/97JD00237.

Mobbs, S. D., and Coauthors, 2005: Observations of downslope winds and rotors in the Falkland Islands. Quart. J. Roy. Meteor. Soc., 131, 329-351, https://doi.org/10.1256/qj.04.51.

Morrison, H., J. A. Curry, and V. I. Khvorostyanov, 2005: A new double-moment microphysics parameterization for application in cloud and climate models. Part I: Description. J. Atmos. Sci., 62, 1665-1677, https://doi.org/10.1175/JAS3446.1.

Nappo, C. J., 2012: An Introduction to Atmospheric Gravity Waves. 2nd ed. Academic Press, 400 pp.

Petersen, G. N., I. A. Renfrew, and G. W. Moore, 2009: An overview of barrier winds off Southeastern Greenland during the Greenland Flow Distortion Experiment. Quart. J. Roy. Meteor. Soc., 135, 1950-1967, https://doi.org/10.1002/qj.455.

Rayleigh, L., 1883: The form of standing waves on the surface of running water. Proc. London Math. Soc., s1-15, 69-78, https:// doi.org/10.1112/plms/s1-15.1.69. 
Ruff, F., and H. Olafsson, 2019: Analysis of observed rapid increases in surface wind speed. Quart. J. Roy. Meteor. Soc., 145, 28-39, https://doi.org/10.1002/qj.3377.

Sawyer, J. S., 1960: Numerical calculation of the displacements of a stratified airstream crossing a ridge of small height. Quart. J. Roy. Meteor. Soc., 86, 326-345, https://doi.org/10.1002/qj.49708636905.

Schär, C., and D. R. Durran, 1997: Vortex formation and vortex shedding in continuously stratified flows past isolated topography. J. Atmos. Sci., 54, 534-554, https://doi.org/10.1175/15200469(1997)054<0534:VFAVSI >2.0.CO;2.

Scorer, R. S., 1949: Theory of waves in the lee of mountains. Quart. J. Roy. Meteor. Soc., 75, 41-56, https:/doi.org/10.1002/qj.49707532308.

Skamarock, W. C., and Coauthors, 2019: A description of the Advanced Research WRF Model version 4. NCAR Tech. Note NCAR/TN-556+STR, 145 pp., http://doi.org/10.5065/1dfh-6p97.

Smith, R. B., 1976: Generation of lee waves by Blue Ridge. J. Atmos. Sci., 33, 507-519, https://doi.org/10.1175/15200469(1976)033<0507:TGOLWB > 2.0.CO;2.

1979: The influence of mountains on the atmosphere. Advances in Geophysics, Vol. 21, Academic Press, 87-230, https://doi.org/10.1016/S0065-2687(08)60262-9.

1987: Aerial observations of the Yugoslavian Bora. J. Atmos. Sci., 44, 269-297, https://doi.org/10.1175/15200469(1987)044<0269:AOOTYB>2.0.CO;2.
Strauss, L., S. Serafin, S. Haimov, and V. Grubišić, 2015: Turbulence in breaking mountain waves and atmospheric rotors estimated from airborne in situ and Doppler radar measurements. Quart. J. Roy. Meteor. Soc., 141, 3207-3225, https://doi.org/10.1002/ qj.2604.

Tewari, M., and Coauthors, 2004: Implementation and verification of the unified NOAH land surface model in the WRF model. 20th Conf. on Weather Analysis and Forecasting/16th Conf. on Numerica Weather Prediction, Seattle, WA, Amer. Meteor. Soc., 14.2A, https://ams.confex.com/ams/pdfpapers/69061.pdf. Vosper, S. B., 2004: Inversion effects on mountain lee waves. Quart. J. Roy. Meteor. Soc., 130, 1723-1748, https://doi.org/10.1256/qj.03.63.

- A. N. Ross, I. A. Renfrew, P. Sheridan, A. D. Elvidge, and V. Grubišić, 2018: Current challenges in orographic flow dynamics: Turbulent exchange due to low-level gravity-wave processes. Atmosphere, 9, 361, https://doi.org/10.3390/atmos9090361.

Wang, T. A., and Y. L. Lin, 2000: Effects of shear and sharp gradients in static stability on two-dimensional flow over an isolated mountain ridge. Meteor. Atmos. Phys., 75, 69-99, https:// doi.org/10.1007/s007030070017.

Wobrock, W., A. Flossman, R. N. Colvile, and D. W. F. Inglis, 1997: Modelling of air flow and cloud fields over the northern Pennines. Atmos. Environ., 31, 2421-2439, https://doi.org/ 10.1016/S1352-2310(96)00287-7. 